\title{
Ion-Exchange and Cation Solvation Reactions in Ti3C2 MXene
}

Michael Ghidiu, Joseph Halim, Sankalp Kota, David Bish, Yury Gogotsi and Michel W.

Barsourm

\section{Linköping University Post Print}

\section{Tweet}

N.B.: When citing this work, cite the original article.

Original Publication:

Michael Ghidiu, Joseph Halim, Sankalp Kota, David Bish, Yury Gogotsi and Michel W. Barsourm, Ion-Exchange and Cation Solvation Reactions in Ti3C2 MXene, 2016, Chemistry of Materials, (28), 10, 3507-3514.

http://dx.doi.org/10.1021/acs.chemmater.6b01275

Copyright: American Chemical Society

http://pubs.acs.org/

Postprint available at: Linköping University Electronic Press

http://urn.kb.se/resolve?urn=urn:nbn:se:liu:diva-129673 


\title{
Ion-Exchange and Cation Solvation Reactions in $\mathrm{Ti}_{3} \mathrm{C}_{2}$ MXene
}

\author{
Michael Ghidiu, ${ }^{\dagger}$ Joseph Halim, ${ }^{\dagger, \S}$ Sankalp Kota, ${ }^{\dagger}$ David Bish, ${ }^{\ddagger}$ Yury Gogotsi, ${ }^{\dagger}, \|$ and
}

Michel W. Barsoum ${ }^{\dagger, *}$

${ }^{\dagger}$ Department of Materials Science and Engineering, Drexel University, Philadelphia, PA 19104

${ }^{\ddagger}$ Department of Geological Sciences, Indiana University, Bloomington, IN 47405

$\S$ Thin Film Physics Division, Department of Physics, Chemistry and Biology (IFM), Linköping University, SE-58183 Linköping (Sweden)

॥ A. J. Drexel Nanomaterials Institute, Drexel University, Philadelphia, PA 19104

\begin{abstract}
Ti}_{3} \mathrm{C}_{2}$ and other two-dimensional transition metal carbides known as MXenes are currently being explored for many applications involving intercalated ions, from electrochemical energy storage, to contaminant sorption from water, to selected ion sieving. We report here a systematic investigation of ion exchange in $\mathrm{Ti}_{3} \mathrm{C}_{2}$ MXene and its hydration/dehydration behavior. We have investigated the effects of the presence of $\mathrm{LiCl}$ during the chemical etching of the MAX phase $\mathrm{Ti}_{3} \mathrm{AlC}_{2}$ into $_{\mathrm{MXene}} \mathrm{Ti}_{3} \mathrm{C}_{2} \mathrm{~T}_{\mathrm{x}}$ ( $\mathrm{T}$ stands for surface termination) and found that the resulting MXene has $\mathrm{Li}^{+}$cations in the interlayer space. We successfully exchanged the $\mathrm{Li}^{+}$cations with $\mathrm{K}^{+}, \mathrm{Na}^{+}, \mathrm{Rb}^{+}, \mathrm{Mg}^{2+}$, and $\mathrm{Ca}^{2+}$ (supported by X-ray photoelectron and energy-dispersive spectroscopy) and found that the exchanged material expands on the unit-cell level in response to changes in humidity, with the nature of expansion dependent on the intercalated cation, similar to behavior of clay minerals; stepwise expansions of the basal spacing were observed, with changes consistent with the size of the $\mathrm{H}_{2} \mathrm{O}$ molecule. Thermogravimetric analysis of the dehydration behavior of these materials shows that the amounts of $\mathrm{H}_{2} \mathrm{O}$ contained at ambient humidity correlates simply with the hydration enthalpy of the intercalated cation, and that the diffusion of the exiting $\mathrm{H}_{2} \mathrm{O}$ proceeds with kinetics similar to clays. These results have implications for understanding, controlling, and exploiting structural changes and $\mathrm{H}_{2} \mathrm{O}$ sorption in MXene films and powders utilized in applications involving ions, such as electrochemical capacitors, sensors, reverse osmosis membranes, or contaminant sorbents.
\end{abstract}

\section{INTRODUCTION}

MXenes - two-dimensional transition metal carbonitrides of the $\mathrm{M}_{\mathrm{n}+1} \mathrm{X}_{\mathrm{n}} \mathrm{T}_{\mathrm{x}}$ composition, where $\mathrm{M}$ is an early transition metal, $\mathrm{X}$ is carbon and/or nitrogen, $\mathrm{n}=1,2,3$, and T represents a variable surface termination ${ }^{1,2}$ such as $\mathrm{O}, \mathrm{OH}, \mathrm{F}$ - are a rapidly-growing class of materials featuring hydrophilicity, high electrical conductivity, and tuneable chemistry and structure. ${ }^{3,4}$ They have been explored in applications from energy storage to water purification to transparent conductive electrodes. ${ }^{5,6,7,8}$ Furthermore, spontaneous intercalation of organic molecules (urea, hydrazine, DMF, etc.), as well as spontaneous and electrochemical intercalation of various cations $\left(\mathrm{Li}^{+}, \mathrm{Na}^{+}, \mathrm{K}^{+}, \mathrm{NH}_{4}^{+}, \mathrm{Mg}^{2+}, \mathrm{Al}^{3+}\right)$ were previously reported. ${ }^{9,10,11}$

Understanding the intercalation chemistry of 2D materials is a prerequisite to many applications. Based on the ability to intercalate cations and the reversible increase in the $c$ lattice parameter (c-LP) with $\mathrm{H}_{2} \mathrm{O}$ uptake, MXenes have been compared with expanding clay minerals. ${ }^{12}$ Although the reversible expansion of clay minerals in $\mathrm{H}_{2} \mathrm{O}$ and the effects of cation exchange have been studied extensively, a fundamental study of the structural effects resulting from cation substitution in MXenes in aqueous, $\mathrm{pH}$-neutral environments has not been undertaken. This is especially pertinent now that a number of MXene applications have been explored involving interactions with salt solutions; for example, when MXenes are used in supercapacitors with aqueous electrolytes, ${ }^{10,13}$ as sorbents for $\mathrm{Pb}$ or $\mathrm{Cr}$ ions, ${ }^{14,15}$ or membranes for ion sieving, the nature of the cation can play a large role in affecting the sorption efficiency or structure and permeability of the membranes. ${ }^{6}$ It has been shown that spontaneous cation intercalation described in reference ${ }^{10}$ may lead to changes in MXene surface chemistry, ${ }^{16}$ but no systematic studies have been reported. If intercalated cations are structurally inherent in MXenes, controlling their concentrations and understanding their effects on interlayer separation can be crucial for tuning electrochemical energy storage, optical, and ion-exchange properties. The drastic changes noticed when $\mathrm{Li}^{+}$ions were presumably intercalated into the MXene structure during synthesis ${ }^{12}$ led us to examine this more 
carefully in a model system, using $\mathrm{Ti}_{3} \mathrm{C}_{2} \mathrm{~T}_{\mathrm{x}}$, to date the most widely studied and best understood MXene member.

The purpose of this work is to investigate cation substitutions and understand how they affect the interlayer spacing of MXenes. Herein, we describe a systematic study of the intercalation of alkali and alkaline earth cations and $\mathrm{H}_{2} \mathrm{O}$ on the interlayer spacing of multilayer $\mathrm{Ti}_{3} \mathrm{C}_{2} \mathrm{~T}_{\mathrm{x}}$ and how these cation-exchanged varieties respond to changes in relative humidity.

\section{EXPERIMENTAL SECTION}

Synthesis of $\mathbf{T i}_{3} \mathbf{A l C}_{2}$. Ti ${ }_{2} \mathrm{AlC}$ powders (-325 mesh, Kanthal, Sweden) were mixed with TiC (Alfa Aesar, 99.5\% purity) and heated to $1350{ }^{\circ} \mathrm{C}$ (at a heating rate of $10^{\circ} \mathrm{C} / \mathrm{min}$ following by a $2 \mathrm{~h}$ soak) to afford $\mathrm{Ti}_{3} \mathrm{AlC}_{2}$, according to previously-reported procedures. ${ }^{17}$ The resulting solid was milled with a milling bit and sieved (-400 mesh) to produce powders under $38 \mu \mathrm{m}$ in size.

Synthesis of $\mathbf{T i}_{3} \mathbf{C}_{2} \mathbf{T}_{\mathbf{x}} \mathbf{H F 1 0}$. Ti $\mathrm{Al}_{3} \mathrm{Al}_{2}$ powder (sieved to $<38$ $\mu \mathrm{m}$ particle size) was slowly added to $10 \mathrm{wt} \%$ hydrofluoric acid (HF) in a ratio of $1 \mathrm{~g} \mathrm{Ti}_{3} \mathrm{AlC}_{2}: 10 \mathrm{~mL}$ etching solution. The reaction mixture was stirred for $24 \mathrm{~h}$ at $25^{\circ} \mathrm{C}$, after which the powders were washed with distilled water in a centrifugation and decantation process: water was added to the reaction mixture, it was shaken for $1 \mathrm{~min}$, then centrifuged for 2 mins to collect the powders. The supernatant was then discarded, and the process repeated. This was done in a ratio of $\sim 0.5 \mathrm{~g}$ powders : $40 \mathrm{~mL}$ water. Upon reaching a $\mathrm{pH}$ of $\sim 5$, the powders were filtered to remove excess water and left for another $24 \mathrm{~h}$ to dry in air.

$\mathbf{T i}_{3} \mathbf{C}_{2} \mathbf{T}_{\mathbf{x}}$ intercalated with ions. Similar to the above procedure, $\mathrm{Ti}_{3} \mathrm{AlC}_{2}$ powder was added to an etching mixture in the same ratio. In this case, however, the etchant was a mixture of $10 \% \mathrm{HF}$ and $\mathrm{LiCl}$. The etchant contained $\mathrm{LiCl}$ in a molar ratio $5 \mathrm{LiCl}: 1$ $\mathrm{Ti}_{3} \mathrm{AlC}_{2}$. The mixture was stirred for $24 \mathrm{~h}$ at $25{ }^{\circ} \mathrm{C}$ followed by washing as described previously.

Acid pre-washing. To remove traces of LiF precipitated during etching, the mixture was washed with a centrifugation procedure as described above, with three washes consisting of $6 \mathrm{M} \mathrm{HCl}$ (Fisher TraceMetal grade). This procedure was performed directly after the etching, before any of the sediments were allowed to dry.

Intercalation / exchange. All samples were acid pre-washed as described above. Before the samples were allowed to dry, salt solutions $\left(1 \mathrm{M} \mathrm{LiCl}, \mathrm{NaCl}, \mathrm{KCl}, \mathrm{RbCl} ; 0.5 \mathrm{M} \mathrm{MgCl}_{2}\right.$ or $\mathrm{CaCl}_{2}$ in distilled water) were added in a ratio of roughly $0.5 \mathrm{~g}$ MXene to 40 $\mathrm{mL}$ solution. After shaking for $2 \mathrm{~min}$, the mixtures were allowed to sit for $1 \mathrm{~h}$. The samples were then centrifuged to settle the powders, and the supernatants were decanted and replaced with fresh solutions. The samples were again shaken and allowed to sit for $24 \mathrm{~h}$. Then they were centrifuged, the supernatants were discarded, and water was added, followed by agitation and centrifugation. After decanting, the sediment was collected via filtration, and washed with distilled water (2 x $5 \mathrm{~mL}$ ) followed by drying in air (roughly $50 \%$ relative humidity) to yield desired powders.

Characterization Techniques. $X$-ray diffraction $(X R D)$ : A diffractometer (Rigaku SmartLab, Rigaku Corporation, Tokyo, Japan) was used to measure XRD patterns $(\mathrm{Cu} \mathrm{K} \alpha$ radiation source). Samples were scanned at a step size of $0.04^{\circ}$ and dwell time of $0.5 \mathrm{~s}$ per step. For measurements on fresh paste samples, before being allowed to dry, the paste was spread into a glass sample holder 0.2 $\mathrm{mm}$ deep with area of $4 \mathrm{~cm}^{2}$ and flattened with a glass slide. Crystalline Si was added as an internal standard for calibrating angles.

$X R D$ with humidity control. Measurements were carried out on a Bruker D8 Advance X-ray powder diffractometer under controlled humidity on a thin-layer slurry mount (quartz zero background) with ambient temperature of $\sim 23^{\circ} \mathrm{C}$ ). Samples were scanned at a step size of $0.02^{\circ}$ and dwell time of $1.0 \mathrm{~s}$ per step. Each change in relative humidity was accompanied by roughly 40 minutes of equilibration time prior to measurement.

$X$-ray photoelectron spectroscopy (XPS). A Physical Electronics VersaProbe 5000 instrument was used employing a $100 \mu \mathrm{m}$ mono- chromatic Al-Ka to irradiate the sample surface. Samples were in the form of cold pressed discs (pressed to $\sim 1 \mathrm{GPa}$ ). Photoelectrons were collected by a $180^{\circ}$ hemispherical electron energy analyzer. Samples were analyzed at a $70^{\circ}$ angle between the sample surface and the path to the analyzer. High-resolution spectra of Ti 2p, C 1s, $\mathrm{O} 1 \mathrm{~s}, \mathrm{~F} 1 \mathrm{~s}, \mathrm{Rb} 3 \mathrm{~d}, \mathrm{Na} 1 \mathrm{~s}$, and $\mathrm{Cl} 2 \mathrm{p}$ were taken at a pass energy of $23.5 \mathrm{eV}$, with a step size of $0.05 \mathrm{eV}$, while for the $\mathrm{Li} 1 \mathrm{~s}$ region the pass energy used was $11.7 \mathrm{eV}$, with the same step size. Postsputtering spectra were taken after the samples were sputtered with an Ar beam operating at $3.8 \mathrm{kV}$ and $150 \mu \mathrm{A}$ for $30 \mathrm{~min}$. All binding energies were referenced to that of the valence band edge at $0 \mathrm{eV}$.

Peak fitting for the high-resolution spectra was performed using CasaXPS Version 2.3.16 RP 1.6. Prior to the peak fitting the background contributions were subtracted using a Shirley function. For the Ti $2 \mathrm{p}_{3 / 2}$ and $2 \mathrm{p}_{1 / 2}, \mathrm{Cl} 2 \mathrm{p}_{3 / 2}$ and $2 \mathrm{p}_{1 / 2}$, and $\mathrm{Rb} 3 \mathrm{~d}_{5 / 2}$ and $3 \mathrm{~d}_{3 / 2}$ components, the intensity ratios of the peaks were constrained to be $2: 1,2: 1$, and 3:2, respectively. The global atomic percentage of the various elements was calculated using the following equation:

$$
X_{i}=100 \frac{A_{i}}{\sum_{j=1}^{\mathrm{m}} A_{j}}
$$

where $X_{i}$ is the atomic concentration of the elemnt (i), $A_{i}$ is the adjusted intensity of element (i), and $A_{j}$ is the total adjusted intensity of all elements. The adjusted intensity is defined as follows:

$$
A_{i}=\frac{I_{i}}{R_{i}}
$$

where $I_{i}$ is the integrated peak area, and $R_{i}$ is the relative sensitivity factor. The atomic percentages of the various species were determined by multiplying the total atomic percentage of each element by the fraction of that element. The total atomic percentage of each element was obtained from the high resolution spectra of that element. High resolution spectra for $\mathrm{Al} 2 \mathrm{p}$ regions is not shown here.

Thermogravimetric Analysis (TGA). TGA was performed on a TA Instruments SDT 2960 Simultaneous DSC-TGA in alumina crucibles under dry nitrogen (Zero Grade 99.998\%, passed through a molecular sieve drying column at $100 \mathrm{cc} \mathrm{min}^{-1}$ ), with a standard of alumina powder. 8-12 mg of $\mathrm{Ti}_{3} \mathrm{C}_{2} \mathrm{~T}_{\mathrm{x}}$ samples were used for each measurement.

\section{RESULTS AND DISCUSSION}

Material production and characterization. Fig. 1 provides a general overview of materials in this report. We first produced $\mathrm{Ti}_{3} \mathrm{C}_{2} \mathrm{~T}_{\mathrm{x}}$ by reaction of $\mathrm{Ti}_{3} \mathrm{AlC}_{2}$ powders with $10 \% \mathrm{HF}$ as reported in Ref. ${ }^{18}$ (denoted here as $\mathrm{Ti}_{3} \mathrm{C}_{2} \mathrm{~T}_{\mathrm{x}}$ HF10). Full procedures are provided in the supporting information. After etching, removal of by-products by washing with water, and drying, we attempted to intercalate $\mathrm{Li}$ by immersion in $1 \mathrm{M}$ aqueous $\mathrm{LiCl}$. Even after $72 \mathrm{~h}$ of exposure, no major changes (not shown) were observed in X-ray diffraction (XRD) patterns.

However, when $\mathrm{LiCl}$ was present as part of the etchant (5 molar equivalents per mole of $\mathrm{Ti}_{3} \mathrm{AlC}_{2}$ ) - rather than as a later addition - an intense and sharp 002 reflection, corresponding to a c-LP of $24.5 \AA$, was observed for the powder dried in ambient air ( 50\% relative humidity for $24 \mathrm{~h}$ ), as opposed to the broader and less intense reflections of 19-20 $\AA$ often observed when only HF was used. ${ }^{9,19}$ Some LiF was identified in XRD patterns of samples at this stage, most likely formed by precipitation through reaction of HF with LiCl. 
Figure 1. Pathway of materials prepared in this report. $\mathrm{Ti}_{3} \mathrm{AlC}_{2}$ MAX phase is etched with a) $10 \% \mathrm{HF}$ alone to remove $\mathrm{Al}$ and yield the MXene $\mathrm{Ti}_{3} \mathrm{C}_{2} \mathrm{~T}_{\mathrm{x}} \mathrm{HF} 10$ ( $\mathrm{T}$ stands for a variable surface termination such as $\mathrm{O}, \mathrm{OH}, \mathrm{F}$ ). This material does not show signs of intercalating cations or water. When etched with b) $10 \% \mathrm{HF}$ in the presence of $\mathrm{LiCl}$ and washed appropriately to remove excess salts, followed by ion exchange, a variety of intercalated MXenes denoted as $A-\mathrm{Ti}_{3} \mathrm{C}_{2} \mathrm{~T}_{\mathrm{x}}$ are produced, where $A$ is an intercalated cation. These materials co-intercalate $\mathrm{H}_{2} \mathrm{O}$ reversibly to produce changes in basal spacing. Note that the illustrations are schematics and not precise structural models.

We modified the washing procedure by adding initial washings of $6 \mathrm{M} \mathrm{HCl}$ to dissolve the $\mathrm{LiF}$ impurity. The material was then immersed in $1 \mathrm{M} \mathrm{LiCl}$ for $24 \mathrm{~h}$ to ensure that $\mathrm{Li}$ remained in the structure and that there was reduced chance for exchange with $\mathrm{H}^{+}$. We designate this material $\mathrm{Li}$ $\mathrm{Ti}_{3} \mathrm{C}_{2} \mathrm{~T}_{\mathrm{x}}$. Figure 2 shows a comparison between the material etched with $\mathrm{HF}$ alone $\left(\mathrm{Ti}_{3} \mathrm{C}_{2} \mathrm{~T}_{\mathrm{x}} \mathrm{HF} 10\right.$, bottom trace) and when $\mathrm{Li}^{+}$ions were intercalated ( $\mathrm{Li}-\mathrm{Ti}_{3} \mathrm{C}_{2} \mathrm{~T}_{\mathrm{x}}$, top trace). It is clear that the presence of $\mathrm{Li}^{+}$leads to greater structural order, and that the ions must be intercalated during etching. It is likely that randomly-distributed $\mathrm{H}_{2} \mathrm{O}$ molecules and varying surface group interactions cause much local variation in the basal spacing of $\mathrm{Ti}_{3} \mathrm{C}_{2} \mathrm{~T}_{\mathrm{x}}-\mathrm{HF} 10$; a layer of dynamic $\mathrm{H}_{2} \mathrm{O}$ and ions in the case of $\mathrm{Li}_{-} \mathrm{Ti}_{3} \mathrm{C}_{2} \mathrm{~T}_{\mathrm{x}}$ could then cause the MXene sheets to be fixed at much more regular separations, leading to higher crystallinity.

Figure 2. Effect of the presence of $\mathrm{LiCl}$ during etching: XRD

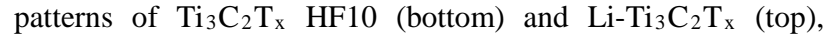
showing higher structural order when $\mathrm{Li}^{+}$ions are present. Vertical dashed lines denote peaks from crystalline Si when included as an internal $2 \theta$ standard. All patterns were measured at $\sim 40 \%$ relative humidity.

To explore the intercalation of other ions, the material was prepared as described with $\mathrm{HF}$ and $\mathrm{LiCl}$ followed by washing with $\mathrm{HCl}$; however, the final immersion in $\mathrm{LiCl}$ was replaced by immersion in $1 \mathrm{M}$ solutions of $\mathrm{NaCl}, \mathrm{KCl}$, or $\mathrm{RbCl}$, or $0.5 \mathrm{M}$ solutions of $\mathrm{MgCl}_{2}$ or $\mathrm{CaCl}_{2}$. This was followed by washing with distilled water to remove traces of salts and drying in air to yield samples denoted as $\mathrm{Na}$ $\mathrm{Ti}_{3} \mathrm{C}_{2} \mathrm{~T}_{\mathrm{x}}, \mathrm{K}-\mathrm{Ti}_{3} \mathrm{C}_{2} \mathrm{~T}_{\mathrm{x}}, \mathrm{Rb}-\mathrm{Ti}_{3} \mathrm{C}_{2} \mathrm{~T}_{\mathrm{x}}, \mathrm{Mg}-\mathrm{Ti}_{3} \mathrm{C}_{2} \mathrm{~T}_{\mathrm{x}}$, and Ca$\mathrm{Ti}_{3} \mathrm{C}_{2} \mathrm{~T}_{\mathrm{x}}$.

We used X-ray photoelectron spectroscopy (XPS) to evaluate our claims of ion intercalation, focusing on $\mathrm{Li}^{-} \mathrm{Ti}_{3} \mathrm{C}_{2} \mathrm{~T}_{\mathrm{x}}$, $\mathrm{Na}-\mathrm{Ti}_{3} \mathrm{C}_{2} \mathrm{~T}_{\mathrm{x}}$, and $\mathrm{Rb}-\mathrm{Ti}_{3} \mathrm{C}_{2} \mathrm{~T}_{\mathrm{x}}$ as examples. A summary of changes specific to intercalated ions is given in Fig. 3 , and full data are given in Figs. S4-S9 and Tables S5-S15. No Lirelated peaks were present, either before or after sputtering, for $\mathrm{Ti}_{3} \mathrm{C}_{2} \mathrm{~T}_{\mathrm{x}} \mathrm{HF} 10$ (Figs. 3a.i and S8.ii, respectively). However, for the $\mathrm{Li}-\mathrm{Ti}_{3} \mathrm{C}_{2} \mathrm{~T}_{\mathrm{x}}$ samples, the spectra before sputtering show the presence of two peaks, one corresponding to an $\mathrm{LiF}$ and/or $\mathrm{LiCl}$ species and one corresponding to $\mathrm{Li}-\mathrm{O}$ and/or Li-OH species (Fig. 3a.ii). The Li-O/Li-OH peak is at a binding energy (BE) of $54.2 \mathrm{eV}$ (all values of the $\mathrm{Li} 1 \mathrm{~s}$ region are presented in Table S12. This species probably originates from the presence of $\mathrm{Li}^{+}$ions interacting with $\mathrm{H}_{2} \mathrm{O}$ or with MXene-bound O-containing groups. ${ }^{20}$ From the Li$\mathrm{O} / \mathrm{Li}-\mathrm{OH}$ peak ratios before sputtering, the amount of $\mathrm{Li}^{+}$ ions is estimated to be $\approx 0.3$ moles per mole of $\mathrm{Ti}_{3} \mathrm{C}_{2}$. The $\mathrm{LiCl} / \mathrm{LiF}$ peak, at a $\mathrm{BE}$ of $56.1 \mathrm{eV}$, is due to the residue of etching, where some $\mathrm{LiF}$ and/or $\mathrm{LiCl}$ salts were not completely removed. After sputtering, the two peaks corresponding to $\mathrm{Li}-\mathrm{O} / \mathrm{Li}-\mathrm{OH}$ and $\mathrm{LiCl} / \mathrm{LiF}$ (Fig. S8.iv) were replaced by one, at a $\mathrm{BE}$ of $55.8 \mathrm{eV}$ (which lies between those for the two species), with the same full-width at half-maximum (FWHM) as the peaks for those species before sputtering. This peak shift might be due to the effect of sputtering on the Li species.

Figures 3b.i and 3b.ii show XPS spectra for the Na 1s region for $\mathrm{Na}-\mathrm{Ti}_{3} \mathrm{C}_{2} \mathrm{~T}_{\mathrm{x}}$, before and after sputtering, respectively. This region was fit by four species, one each to $\mathrm{NaF} / \mathrm{NaCl}$ and $\mathrm{NaOH} / \mathrm{Na}_{2} \mathrm{O}^{21-23}$ The former likely results from incomplete washing of $\mathrm{NaCl}$ salts and the possible formation of $\mathrm{NaF}$. The latter likely originates from intercalated $\mathrm{Na}^{+}$ions. The other two species originate from the Ti LMM Auger lines and correspond to the Ti-C species in MXene and $\mathrm{TiO}_{2}$ (surface oxides). ${ }^{24}$ It is worth noting that the $\mathrm{BE}$ of all these species shifts to a slightly higher BE (about 0.1 to $0.2 \mathrm{eV}$ ) after sputtering. Again, this might be an effect of the sputtering process. The amount of $\mathrm{Na}^{+}$intercalant per mole of $\mathrm{Ti}_{3} \mathrm{C}_{2}$, estimated from the XPS spectra, was $\approx 0.24$ moles (before sputtering). XPS spectra of the Li 1s region for Na$\mathrm{Ti}_{3} \mathrm{C}_{2} \mathrm{~T}_{\mathrm{x}}$ before sputtering (Fig. 3a.iii) show no sign of Li$\mathrm{O} / \mathrm{Li}-\mathrm{OH}$ species, with only a peak for $\mathrm{LiF} / \mathrm{LiCl}$ species. This holds true after sputtering as well (Fig. S8.vi). The lack of a peak corresponding to intercalated $\mathrm{Li}^{+}$suggests complete exchange between $\mathrm{Li}^{+}$and $\mathrm{Na}^{+}$ions. XPS spectra of the $\mathrm{Rb}-\mathrm{Ti}_{3} \mathrm{C}_{2} \mathrm{~T}_{\mathrm{x}}$ samples were similar; the disappearance of the $\mathrm{Li}^{+}$species in the $\mathrm{Li}$ 1s region (Fig. 3a.iv and S8.viii) is associated with the appearance of a species in the $\mathrm{Rb} 3 \mathrm{~d}$ region (Fig. 3c). ${ }^{25}$ The amount of $\mathrm{Rb}$ species intercalated per mole of $\mathrm{Ti}_{3} \mathrm{C}_{2}$, estimated from the XPS spectra, was $\approx 0.16$ moles (before sputtering). A summary of the MXene chemistries obtained from the XPS peak fittings in a similar manner as in Ref. 1 is shown in Table S7.

We did not carry out XPS measurements on $\mathrm{K}-\mathrm{Ti}_{3} \mathrm{C}_{2} \mathrm{~T}_{\mathrm{x}}$, $\mathrm{Mg}-\mathrm{Ti}_{3} \mathrm{C}_{2} \mathrm{~T}_{\mathrm{x}}$, or $\mathrm{Ca}-\mathrm{Ti}_{3} \mathrm{C}_{2} \mathrm{~T}_{\mathrm{x}}$. Energy-dispersive $\mathrm{X}$-ray spectroscopy (EDS) of these and other samples supported the presence of cations without proportionate amounts of $\mathrm{Cl}$ (Fig. S1 and Table S1). From these data, we determined approximate cation amounts per $\mathrm{Ti}_{3} \mathrm{C}_{2}$ for Na-, Mg-, K-, and $\mathrm{Rb}-\mathrm{Ti}_{3} \mathrm{C}_{2} \mathrm{~T}_{\mathrm{x}}$ to be $\sim 0.18,0.08,0.17$, and 0.25 , respectively. The amount of $\mathrm{Cl}$ was consistent across all samples and is probably present as a chloride salt impurity or a minor surface termination.

Figure 3. XPS spectra with curve-fitting for: a) Li 1s region for, (i) $\mathrm{Ti}_{3} \mathrm{C}_{2} \mathrm{~T}_{\mathrm{x}}$ HF10, (ii) $\mathrm{Li}-\mathrm{Ti}_{3} \mathrm{C}_{2} \mathrm{~T}_{\mathrm{x}}$, (iii) $\mathrm{Na}-\mathrm{Ti}_{3} \mathrm{C}_{2} \mathrm{~T}_{\mathrm{x}}$, (iv) Rb$\mathrm{Ti}_{3} \mathrm{C}_{2} \mathrm{~T}_{\mathrm{x}}$, all before sputtering. Dashed vertical lines represent, from left to right, species $\mathrm{LiF} / \mathrm{LiCl}$ and $\mathrm{LiOH} / \mathrm{Li}_{2} \mathrm{O}$; the large shoulder on the left is due to the $\mathrm{Ti}$ 3s peak (See supporting information for the complete region of the spectra, Fig. S8 and Table S12); b) Na 1s region for $\mathrm{Na}_{-}-\mathrm{Ti}_{3} \mathrm{C}_{2} \mathrm{~T}_{\mathrm{x}}$ (i) before and (ii) after sputtering. Dashed vertical lines, from left to right, represent the species $\mathrm{NaOH}$ ( $\mathrm{Na} 1 \mathrm{~s}$ ), $\mathrm{NaF} / \mathrm{NaCl}$ ( $\mathrm{Na} 1 \mathrm{~s}$ ), Ti-C (Auger LMM line), and $\mathrm{TiO}_{2}$ (Auger LMM line), respectively and; c) $\mathrm{Rb} 3 \mathrm{~d}$ region for $\mathrm{Rb}-\mathrm{Ti}_{3} \mathrm{C}_{2} \mathrm{~T}_{\mathrm{x}}$ (i) before and (ii) after sputtering. 
Dashed vertical lines, from right to left, represent the species $\mathrm{Rb}^{+}\left(3 \mathrm{~d}_{5 / 2}\right), \mathrm{RbCl}\left(3 \mathrm{~d}_{5 / 2}\right), \mathrm{Rb}^{+}\left(3 \mathrm{~d}_{3 / 2}\right)$, and $\mathrm{RbCl}\left(3 \mathrm{~d}_{3 / 2}\right)$, respectively.

It is difficult to compare the cation amounts obtained from XPS with those obtained from EDS, as XPS is more surfacesensitive and considers different species, whereas EDS has a greater penetration depth but insufficient resolution to distinguish various species. Given these differences between the two methods, we find agreement to be mostly reasonable. As discussed below, the varied responses of these MXenes to humidity conditions is strong evidence for the intercalation of $\mathrm{K}, \mathrm{Mg}$, and Ca.

In-situ XRD with humidity control. It is well established that many clay materials exhibit different structural responses to changes in relative humidity $(\mathrm{RH})$ or water activity. ${ }^{26,27}$ As this has not yet been explored in MXene, we set out to characterize the response of ion-exchanged $\mathrm{Ti}_{3} \mathrm{C}_{2} \mathrm{~T}_{\mathrm{x}}$ to changes in $\mathrm{RH}$, using XRD to track the $00 \mathrm{l}$ reflections (related to the c-LP). For this study we measured the samples $\mathrm{K}-\mathrm{Ti}_{3} \mathrm{C}_{2} \mathrm{~T}_{\mathrm{x}}, \mathrm{Li}-\mathrm{Ti}_{3} \mathrm{C}_{2} \mathrm{~T}_{\mathrm{x}}, \mathrm{Na}-\mathrm{Ti}_{3} \mathrm{C}_{2} \mathrm{~T}_{\mathrm{x}}, \mathrm{Mg}-$ $\mathrm{Ti}_{3} \mathrm{C}_{2} \mathrm{~T}_{\mathrm{x}}$, and $\mathrm{Ca}-\mathrm{Ti}_{3} \mathrm{C}_{2} \mathrm{~T}_{\mathrm{x}}$. RH was varied between $\sim 0$ and $95 \%$, with $\sim 40$ minutes given for equilibration before each measurement. The results are shown in Fig. 4. 3D plots in Fig. 4a show how the $2 \theta$ of the 002 reflection for $\mathrm{Ti}_{3} \mathrm{C}_{2}$ exchanged with various cations shifted as the $\mathrm{RH}$ dropped from $95 \%$ to $\sim 0 \%$ and then increased again to the initial humidity. The same data are presented superimposed as more typical intensity vs. $2 \theta \mathrm{XRD}$ patterns in Fig. $4 \mathrm{~b}$ so that the shape of the peaks can be seen. The positions of the reflections, at maximum intensity, are summarized as a function of RH in Fig. 4c. It is immediately clear that: (1) the reflections do not shift continuously; there are only two major reflections, with no peaks in between and, (2) different cations result in very different responses.

Figure 4. a) 3D plots of the 002 region of $A-\mathrm{Ti}_{3} \mathrm{C}_{2} \mathrm{~T}_{\mathrm{x}}$ (with each intercalated cation $A$ denoted at left), as $\mathrm{RH}$ was varied from $95 \%$ to $\sim 0$ and back to $95 \%$. The color scheme represents diffraction intensity, with red being highest and blue lowest. b) the same data, where the peaks are superimposed and presented as intensity versus $2 \theta$ plots, to better illustrate the shape of the diffraction peaks used to generate the 3D plots. Solid blue traces denote the initial condition at $95 \% \mathrm{RH}$, red traces denote the material at $0 \% \mathrm{RH}$, and dashed blue traces denote the material after return to $95 \%$ RH. c) $c$ ( $2 \times$ d $\left._{002}\right)$ extracted from the peaks shown in a and b, as a function of RH. Green down triangles represent the path from $95 \%$ to $0 \% \mathrm{RH}$ and red up triangles the path from $0 \%$ to $95 \% \mathrm{RH}$ following the down path. Data are organized by intercalated cation in order of increasing hydration enthalpy.

The $c$ of all samples at $\sim 0 \% \mathrm{RH}$ is roughly $25 \AA$, which contrasts with that of MXene under similar conditions produced using $\mathrm{HF}$ alone - viz. $\mathrm{Ti}_{3} \mathrm{C}_{2} \mathrm{~T}_{\mathrm{x}} \mathrm{HF} 10$ - at $\sim 20 \AA{ }^{2} \mathrm{a}$ difference corresponding roughly to the diameter of an $\mathrm{H}_{2} \mathrm{O}$ molecule. We believe this $25 \AA$-phase is intercalated with a single layer of $\mathrm{H}_{2} \mathrm{O}$ molecules (this type of structure has been suggested for MXenes previously ${ }^{28}$ ). Almost all sam- ples, with the exception of $\mathrm{K}-\mathrm{Ti}_{3} \mathrm{C}_{2} \mathrm{~T}_{\mathrm{x}}$, experienced a discontinuous shift in $c$ at high humidities of the order of $+3 \AA$ per interlayer, most probably due to the presence of a bilayer $\mathrm{H}_{2} \mathrm{O}$ structure, as has been observed in other materials. ${ }^{29,30,31}$

These results imply that the RH at which expansion from the monolayer structure occurs is related to the hydration enthalpy of the cation (Table S2), with the $\mathrm{K}^{+}$samples showing almost no expansion and the $\mathrm{Mg}^{2+}$ samples showing almost no single- $\mathrm{H}_{2} \mathrm{O}$-layer form until very low humidities. The simplest physical explanation is that there is an energy requirement to separate the $\mathrm{Ti}_{3} \mathrm{C}_{2} \mathrm{~T}_{\mathrm{x}}$ sheets, which is overcome by the hydration of the intercalated cation; the divalent cations have a sufficiently high driving force (related to hydration enthalpy) to form a bilayer $\mathrm{H}_{2} \mathrm{O}$ structure in the MXene interlayer at moderate humidity, whereas $\mathrm{Li}^{+}$and $\mathrm{Na}^{+}$require higher $\mathrm{RH}$ due to their lower hydration energies, and $\mathrm{K}^{+}$is unable to stabilize a bilayer. This behavior is parallel with the behavior noted in numerous studies of smectites, showing a direct link to hydration energy of interlayer cations, with a secondary effect from the charge on the individual silicate layers. ${ }^{32,33}$ In addition, XRD data, for all but the Kexchanged sample, reveal significant hysteresis between the hydration and dehydration branches, which is also consistent with this suggested hydration behavior. This can be seen, for example, in the marked difference in the $\mathrm{RH}$ value required for $\mathrm{Ca}-\mathrm{Ti}_{3} \mathrm{C}_{2} \mathrm{~T}_{\mathrm{x}}$ to change between the monolayer and bilayer structure on hydration ( 50\% RH) and dehydration ( $20 \% \mathrm{RH})$. To confirm that no other major structural changes were occurring between hydration and dehydration, full XRD patterns including the $h k l 2 \theta$ regions were recorded for $\mathrm{Ca}-\mathrm{Ti}_{3} \mathrm{C}_{2} \mathrm{~T}_{\mathrm{x}}$ at $95 \%$ and $\sim 0 \% \mathrm{RH}$ and are reported in Fig. S2. There is no change in the position of the 110 peak, signifying no change of structure along the direction parallel to the basal planes. ${ }^{12}$

Figure 5. 3D plot for dehydration of initially wet $\mathrm{Li}_{-} \mathrm{Ti}_{3} \mathrm{C}_{2} \mathrm{~T}_{\mathrm{x}}$ in an environment of $\sim 40 \% \mathrm{RH}$ and $25{ }^{\circ} \mathrm{C}$. The heat plot is composed of XRD patterns where red represents the highest diffraction intensity and blue the lowest. The original patterns are shown superimposed (above) and stacked (right) for clarity on the construction of the heat plot. The blue XRD pattern represents $\mathrm{Li}-\mathrm{Ti}_{3} \mathrm{C}_{2} \mathrm{~T}_{\mathrm{x}}$ in the presence of liquid water, and the red plot is the pattern once the transition has completed.

Finally, in a separate experiment, $\mathrm{Li}-\mathrm{Ti}_{3} \mathrm{C}_{2} \mathrm{~T}_{\mathrm{x}}$ was saturated with liquid water and allowed to equilibrate in an ambient atmosphere of $\sim 40 \% \mathrm{RH}$ while XRD patterns were recorded roughly every 4 minutes as the liquid water evaporated; these are presented as a 3D plot in Fig. 5. This provides some insight into the timescale - roughly an hour - of the bilayer-to-monolayer transformation at a typical ambient $\mathrm{RH}$. Further, this experiment demonstrates conclusively that the transition involves a discontinuous jump in c-LP - any continuous change that could hide during the equilibrations between measurements in the RH-controlled XRD (Fig. 4) would be apparent here.

Thermogravimetric Analysis. To evaluate the connection between the expansion of the layers and the amount of intercalated $\mathrm{H}_{2} \mathrm{O}$, we performed thermogravimetric analysis

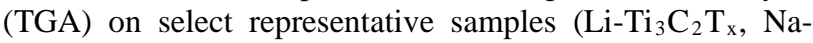


$\mathrm{Ti}_{3} \mathrm{C}_{2} \mathrm{~T}_{\mathrm{x}}, \mathrm{K}-\mathrm{Ti}_{3} \mathrm{C}_{2} \mathrm{~T}_{\mathrm{x}}$, and $\mathrm{Ca}-\mathrm{Ti}_{3} \mathrm{C}_{2} \mathrm{~T}_{\mathrm{x}}$ ) (Fig. 6). All samples were first equilibrated at $\sim 50 \% \mathrm{RH}$ at $25{ }^{\circ} \mathrm{C}$, and TGA was subsequently performed in various temperature steps (Fig. 6a), ramping stepwise up to $120^{\circ} \mathrm{C}$. In order to compare and interpret results, we made the assumption that most of the $\mathrm{H}_{2} \mathrm{O}$ associated with cations - i.e., $\mathrm{H}_{2} \mathrm{O}$ of hydration - was removed after heating using the temperature program shown in Fig. 6a. Normalizing the weight loss results by the weight 250 minutes after the start of the experiments gave the massloss curves shown in Fig. 6a. Each sample was maintained at $\sim 27{ }^{\circ} \mathrm{C}$ under a $100 \mathrm{cc} / \mathrm{min}$ flow of dry $\mathrm{N}_{2}$ for the first segment in the temperature program. We compared TGA and $\mathrm{XRD}$ data for each sample under comparable conditions to formulate a structural model for dehydration; the material should undergo the same changes during TGA from its initial state $\left(50 \% \mathrm{RH}, 25^{\circ} \mathrm{C}\right.$ ) to the end of the first step ( 0\% $\mathrm{RH}, 27^{\circ} \mathrm{C}$ ) as it did over the same $\mathrm{RH}$ range in XRD experiments. In other words, the fact that $\mathrm{Ca}-\mathrm{Ti}_{3} \mathrm{C}_{2} \mathrm{~T}_{\mathrm{x}}$ has the highest mass loss during this step is consistent with it having the greatest $\Delta \mathrm{c}-\mathrm{LP}$ as seen from XRD (taken to be an $\mathrm{H}_{2} \mathrm{O}$ bilayer-to-monolayer transition). The TGA data show that all samples lose $\mathrm{H}_{2} \mathrm{O}$, even without major change in $c$ (in the case of $\mathrm{K}^{+}, \mathrm{Na}^{+}$, and $\mathrm{Li}^{+}$samples), so it is important to address whether the desorbed $\mathrm{H}_{2} \mathrm{O}$ originates from the interlayer (leading to structural changes observable in XRD) or from surface-adsorbed water outside the particles. Based on work on clay minerals, ${ }^{34}$ we believe that, after equilibration at $50 \% \mathrm{RH}$, the dominant contribution to desorbable $\mathrm{H}_{2} \mathrm{O}$ will come from the interlayer, rather than inter-particle pores or surface-adsorbed $\mathrm{H}_{2} \mathrm{O}$ (see Fig. S3 for a typical distribution of particle sizes; the particles should be large enough that their outside surface area is much smaller relative to the amount of interlayer space).

Further, sample Ca- $\mathrm{Ti}_{3} \mathrm{C}_{2} \mathrm{~T}_{\mathrm{x}}$ demonstrates a clear discontinuous bilayer-to-monolayer transition at low $\mathrm{RH}$ but a more continuous change in the weight loss at $27^{\circ} \mathrm{C}$; we believe that as $\mathrm{H}_{2} \mathrm{O}$ evolves from the structure, pillars of hydrated cations remain until the abrupt transition, at which point $\mathrm{H}_{2} \mathrm{O}$ supporting the expanded structure is removed, leaving monolayer $\mathrm{H}_{2} \mathrm{O}$ between the collapsed basal planes.

A plot of the normalized mass fraction against ion hydration enthalpy is nearly linear (Fig. 6b), strongly supporting the idea that the bulk of the $\mathrm{H}_{2} \mathrm{O}$ initially present in the structure at $50 \% \mathrm{RH}$ is hydrating the cations. After initial dehydration at $27{ }^{\circ} \mathrm{C}$, samples were equilibrated at $40{ }^{\circ} \mathrm{C}$, and after this step, there was no longer a strong dependence on the hydration enthalpy, which can clearly be seen after 80 ${ }^{\circ} \mathrm{C}$ equilibration. Linear fits to the initial and $27{ }^{\circ} \mathrm{C}$ data share the y-intercept; the plot in Fig. $6 \mathrm{~b}$ is divided into regions that show strong dependence on cations (green shaded area) and further weight loss (red shaded area) that is attributed to $\mathrm{H}_{2} \mathrm{O}$ adsorbed to MXene surfaces. Considering the $\mathrm{H}_{2} \mathrm{O}$ lost in the region that shows strong dependence on cation hydration enthalpy, we estimate the number of $\mathrm{H}_{2} \mathrm{O}$ per $\mathrm{Ti}_{3} \mathrm{C}_{2}$ formula unit at $50 \% \mathrm{RH}$ to be $0.18,0.24,0.29$, and 0.91 for $\mathrm{Ti}_{3} \mathrm{C}_{2} \mathrm{~T}_{\mathrm{x}}$ intercalated with $\mathrm{K}^{+}, \mathrm{Na}^{+}, \mathrm{Li}^{+}$, and $\mathrm{Ca}^{2+}$, respectively. We note that these values fall within a range observed for similar materials. ${ }^{30,35}$ Full data for this derivation are provided in Tables S3-S4. Some samples from the diffraction study were not used in the TGA study due to time constraints, but we feel that the ion-intercalated samples selected give a representative picture.
Figure 6. a) Temperature during the TGA runs, showing the stepwise programming, beginning at $27^{\circ} \mathrm{C}$ and ramping to 40 ${ }^{\circ} \mathrm{C}, 80^{\circ} \mathrm{C}$, and $120^{\circ} \mathrm{C}$ with $1 \mathrm{~h}$ of equilibration time during each step (right axis). Data are not smoothed. Mass fraction for selected ion-intercalated samples is shown on the left axis. All mass changes were normalized by their mass after 250 mins from the start of heating, assuming that most $\mathrm{H}_{2} \mathrm{O}$ had been removed at that point. b) The same mass fraction data from (a) initially, and after equilibration steps, plotted against cation hydration enthalpy. Linear regression fits are shown above each data set. The green shaded area represents mass loss more strongly correlated with ion hydration enthalpy, and the red shaded area represents loss of additional $\mathrm{H}_{2} \mathrm{O}$. Note that the $x$ axis begins at $200 \mathrm{~kJ} / \mathrm{mol}$.

Bray and Redfern ${ }^{36}$ applied the Avrami equation to thermal analysis data for Ca-montmorillonite, an expanding clay mineral intercalated with $\mathrm{Ca}^{2+}$, to determine the kinetics and mechanism of diffusion of $\mathrm{H}_{2} \mathrm{O}$ from the structure. The equation

$$
\ln (-\ln (1-\alpha))=m \ln k+m \ln t,
$$

where $t$ is time in seconds, and $\alpha$ is the extent of reaction (a value from 0 to 1 ), can be used with weight loss data. The rate constant $k$ and a parameter related to the reaction mechanism, $m$, can be extracted from the slope and intercepts ( $k$ and $k \ln m$, respectively). Bray and Redfern found that, for dehydration at 20 and $30{ }^{\circ} \mathrm{C}$ in a dry $\mathrm{N}_{2}$ atmosphere, their Ca-montmorillonite gave $m$ values between 0.6 , associated with 2-D diffusion-controlled reactions, and 1.0, associated with a first-order process; they suggested a first-order process that was slowed by diffusion through the interlayers.

Plots of $\alpha$ vs. time for our materials are shown in Fig. 7a (derived by taking the initial mass percent at a given temperature step as $\alpha=0$ and the mass percent at $\sim$ equilibrium as $\alpha=1$ ). Linearizations according to the equation above are plotted in Fig. 7b to extract $k$ and $m$ (for these, $\alpha$ was taken between 0.15 and 0.5 ). Our data at $27{ }^{\circ} \mathrm{C}$ provide $k$ and $m$

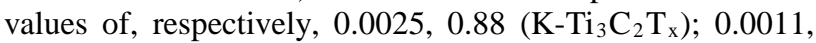

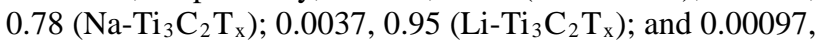
$0.80\left(\mathrm{Ca}-\mathrm{Ti}_{3} \mathrm{C}_{2} \mathrm{~T}_{\mathrm{x}}\right)$. The values for $\mathrm{Ca}-\mathrm{Ti}_{3} \mathrm{C}_{2} \mathrm{~T}_{\mathrm{x}}$ compare favorably with those of Bray and Redfern's Camontmorillonite, namely $0.0008,0.99$ at $20^{\circ} \mathrm{C}$ and 0.0033 , 0.86 at $30^{\circ} \mathrm{C}$. Based on the similarity between the values of these parameters for our material and Ca-montmorillonite, it is reasonable to conclude that a similar process of $\mathrm{H}_{2} \mathrm{O}$ loss from the interlayers is occurring in our samples. However, more careful work - with controlled particle sizes, and various controlled atmospheres - is needed to fully understand the dehydration mechanisms. These initial findings on the kinetics of dehydration should help shape decisions made in material processing and handling in terms of how to control water content. 
Figure 7. a) Plot of $\alpha$ against time at $27{ }^{\circ} \mathrm{C}$ for $\mathrm{K}_{-} \mathrm{Ti}_{3} \mathrm{C}_{2} \mathrm{~T}_{\mathrm{x}}$, Na$\mathrm{Ti}_{3} \mathrm{C}_{2} \mathrm{~T}_{\mathrm{x}}, \mathrm{Li}_{-} \mathrm{Ti}_{3} \mathrm{C}_{2} \mathrm{~T}_{\mathrm{x}}$, and $\mathrm{Ca}-\mathrm{Ti}_{3} \mathrm{C}_{2} \mathrm{~T}_{\mathrm{x}}$. b) linearization of data from (a) in Avrami analysis to extract $k$ and $m$ values.

It is significant that our observations are in agreement with the behavior observed for other layered materials, such as clays and sulfides of transition metals. The layered ternary sulfides are likely better analogs to MXenes than swelling clays in terms of properties and applications, because some of them are electrically conductive, whereas clays are chemically closer to MXenes due to their $\mathrm{O} / \mathrm{OH}$ surface terminations. Lerf and Schöllhorn studied solvation effects of $\mathrm{A}_{\mathrm{x}} \mathrm{TiS}_{2}, \mathrm{~A}_{\mathrm{x}} \mathrm{NbS}_{2}$, and $\mathrm{A}_{\mathrm{x}} \mathrm{TaS}_{2}$, where $\mathrm{A}$ is a group-1 or group-2 cation. ${ }^{29}$ They found that c-LP expansion could be related to the hydration properties of the various A cations and were weak functions of the transition metal, viz. Ti, Nb or Ta. This suggests that MXenes containing other transition metals (V, Nb, Mo, Ta, etc. $\left.{ }^{4}\right)$ may behave similarly to $\mathrm{Ti}_{3} \mathrm{C}_{2} \mathrm{~T}_{\mathrm{x}}$, even though this comparison should be verified by experiments on other MXenes. Lerf and Schöllhorn also documented discrete hydration stages that depended on the activity of $\mathrm{H}_{2} \mathrm{O}$, corresponding to monolayers or bilayers of intercalated $\mathrm{H}_{2} \mathrm{O}$, as has been extensively documented for swelling clay minerals. Whittingham also observed similar behavior in terms of cation hydration. ${ }^{37}$ Most notable in these systems (and in swelling clay systems), especially the Ti-based dichalcogenides, is that $\mathrm{Li}^{+}, \mathrm{Na}^{+}$, and the divalent cations are able to stabilize $\mathrm{H}_{2} \mathrm{O}$ bilayers, which is exactly the case observed here for $\mathrm{Ti}_{3} \mathrm{C}_{2} \mathrm{~T}_{\mathrm{x}}$.

\section{CONCLUSIONS}

We have demonstrated that etching of $\mathrm{Ti}_{3} \mathrm{AlC}_{2}$ to produce $\mathrm{Ti}_{3} \mathrm{C}_{2} \mathrm{~T}_{\mathrm{x}}$ with the combination of $\mathrm{HF}$ and $\mathrm{LiCl}$ can yield MXenes with different characteristics than those produced with HF alone, and we provide evidence that this material behaves like swelling clay minerals and metal dichalcogenides. Through XPS and EDS analyses, we demonstrate the cation exchange of $\mathrm{Li}^{+}$with $\mathrm{Na}^{+}, \mathrm{K}^{+}, \mathrm{Rb}^{+}, \mathrm{Mg}^{2+}$, and $\mathrm{Ca}^{2+}$. These cations, in turn, give rise to quite different structural changes in response to $\mathrm{RH}$, as evidenced by $\mathrm{XRD}$, involving a discontinuous structural expansion in the direction normal to the basal plane as $\mathrm{H}_{2} \mathrm{O}$ molecules intercalate. TGA data support the idea that the expansion is caused by $\mathrm{H}_{2} \mathrm{O}$ associated with the cations, and the excellent correlation with hydration enthalpy supports the conclusion that this $\mathrm{H}_{2} \mathrm{O}$ lost originates from hydration of alkali metal ions intercalated between the MXene layers. Further, Avrami-type analysis of the TGA data suggests reaction mechanisms in agreement with these reported for Ca-montmorillonite, a swelling clay with surface functionalities similar to MXene.

The findings from this study potentially impact the use of MXenes in many applications. For electrochemical energy storage, the ion permeability and hence rate performance is related to the interlayer spacing of the MXene sheets; the results here may guide the rational selection of electrolytes or the initial ion composition of the starting MXene. For applications involving water purification or desalination, interations with other ions in the solution (for example municipal water or seawater), especially involving the structural changes or durability of MXene films, will be important considerations. Finally, due to MXene's inherent high con- ductivity, we imagine applications in which the conductivity can be modulated in response to changing $\mathrm{RH}$.

\section{ASSOCIATED CONTENT}

Supporting Information Available: Energy-dispersive $\mathrm{X}$-ray spectroscopy, scanning electron microscopy, additional X-ray diffraction patterns, thermogravimetric analysis, and full X-ray photoelectron spectroscopy data. This material is available free of charge via the Internet at http://pubs.acs.org.

\section{ACKNOWLEDGEMENTS}

This work was supported by the US National Science Foundation under Grant No. DMR-1310245; M.G. was supported by the National Science Foundation Graduate Research Fellowship under Grant 283036-3304. M.W.B. and J.H. were supported through Swedish Research Council (Project Grant No. 6212012-4430), the Swedish Foundation for Strategic Research through the Synergy Grant FUNCASE Functional Carbides for Advanced Surface Engineering. We thank the Drexel Core Facility and staff for assistance with characterisation involving SEM, EDS, XRD, and XPS. Collaboration between Drexel University and Indiana University was supported by the Fluid Interface Reactions, Structures and Transport (FIRST) Center, an Energy Frontier Research Center funded by the U.S. Department of Energy, Office of Science, and Office of Basic Energy Sciences. The authors are grateful for help and discussions to Dr. David J. Wesolowski and Dr. Hsiu-Wen Wang from the Oak Ridge National Laboratory, who initiated this collaboration.

\section{AUTHOR INFORMATION}

Corresponding Author

*E-mail: barsoumw@drexel.edu

Notes

The authors declare no competing financial interest.

\section{REFERENCES}

(1) Halim, J.; Cook, K. M.; Naguib, M.; Eklund, P.; Gogotsi, Y.; Rosen, J.; Barsoum, M. W. X-Ray Photoelectron Spectroscopy of Select Multi-Layered Transition Metal Carbides (MXenes). Appl. Surf. Sci. 2016, 362, 406-417.

(2) Wang, H.-W.; Naguib, M.; Page, K.; Wesolowski, D. J.; Gogotsi, Y. Resolving the Structure of $\mathrm{Ti}_{3} \mathrm{C}_{2} \mathrm{~T}_{x}$ MXenes through Multilevel Structural Modeling of the Atomic Pair Distribution Function. Chem. Mater. 2016, 28, 349-359.

(3) Naguib, M.; Mashtalir, O.; Carle, J.; Presser, V.; Lu, J.; Hultman, L.; Gogotsi, Y.; Barsoum, M. W. TwoDimensional Transition Metal Carbides. ACS Nano 2012, 6, 1322-1331.

(4) Naguib, M.; Mochalin, V. N.; Barsoum, M. W.; Gogotsi, Y. 25th Anniversary Article: MXenes: A New Family of Two-Dimensional Materials. Adv. Mater. 2014, 26, 992-1005. 
Xie, Y.; Dall'Agnese, Y.; Naguib, M.; Gogotsi, Y.; Barsoum, M. W.; Zhuang, H. L.; Kent, P. R. C. Prediction and Characterization of MXene Nanosheet Anodes for Non-Lithium-Ion Batteries. ACS Nano 2014, 8, 9606-9615.

(6) Ren, C. E.; Hatzell, K. B.; Alhabeb, M.; Ling, Z.; Mahmoud, K. A.; Gogotsi, Y. Charge- and SizeSelective Ion Sieving Through $\mathrm{Ti}_{3} \mathrm{C}_{2} \mathrm{~T}_{x}$ MXene Membranes. J. Phys. Chem. Lett. 2015, 6, 4026-4031.

(7) Halim, J.; Lukatskaya, M. R.; Cook, K. M.; Lu, J.; Smith, C. R.; Näslund, L.-Å.; May, S. J.; Hultman, L.; Gogotsi, Y.; Eklund, P.; Barsoum, M. W. Transparent Conductive Two-Dimensional Titanium Carbide Epitaxial Thin Films. Chem. Mater. 2014, 26, 2374-2381.

(8) Yu, Y.-X. Prediction of Mobility, Enhanced Storage Capacity, and Volume Change during Sodiation on Interlayer-Expanded Functionalized $\mathrm{Ti}_{3} \mathrm{C}_{2}$ MXene Anode Materials for Sodium-Ion Batteries. J. Phys. Chem. C 2016, 120, 5288-5296.

(9) Mashtalir, O.; Naguib, M.; Mochalin, V. N.; Dall’Agnese, Y.; Heon, M.; Barsoum, M. W.; Gogotsi, Y. Intercalation and Delamination of Layered Carbides and Carbonitrides. Nat. Commun. 2013, 4, 1716.

(10) Lukatskaya, M. R.; Mashtalir, O.; Ren, C. E.; Dall'Agnese, Y.; Rozier, P.; Taberna, P. L.; Naguib, M.; Simon, P.; Barsoum, M. W.; Gogotsi, Y. Cation Intercalation and High Volumetric Capacitance of TwoDimensional Titanium Carbide. Science 2013, 341, 1502-1505.

(11) Levi, M. D.; Lukatskaya, M. R.; Sigalov, S.; Beidaghi, M.; Shpigel, N.; Daikhin, L.; Aurbach, D.; Barsoum, M. W.; Gogotsi, Y. Solving the Capacitive Paradox of 2D MXene Using Electrochemical Quartz-Crystal Admittance and In Situ Electronic Conductance Measurements. Adv. Energy Mater. 2014, 5, 1400815. doi: 10.1002/aenm.201400815

(12) Ghidiu, M.; Lukatskaya, M. R.; Zhao, M.-Q.; Gogotsi, Y.; Barsoum, M. W. Conductive Two-Dimensional Titanium Carbide "clay" with High Volumetric Capacitance. Nature 2014, 516, 78-81.

(13) Wang, X.; Kajiyama, S.; Iinuma, H.; Hosono, E.; Oro, S.; Moriguchi, I.; Okubo, M.; Yamada, A. Pseudocapacitance of MXene Nanosheets for High-Power Sodium-Ion Hybrid Capacitors. Nat. Commun. 2015, 6, 6544.

(14) Ying, Y.; Liu, Y.; Wang, X.; Mao, Y.; Cao, W.; Hu, P.; Peng, X. Two-Dimensional Titanium Carbide for Efficiently Reductive Removal of Highly Toxic Chromium(VI) from Water. ACS Appl. Mater. Interfaces 2015, 7, 1795-1803.

(15) Peng, Q.; Guo, J.; Zhang, Q.; Xiang, J.; Liu, B.; Zhou, A.; Liu, R.; Tian, Y. Unique Lead Adsorption Behavior of Activated Hydroxyl Group in Two-Dimensional Titanium Carbide. J. Am. Chem. Soc. 2014, 136, 41134116.
(16)

Dall’Agnese, Y.; Lukatskaya, M. R.; Cook, K. M.; Taberna, P.-L.; Gogotsi, Y.; Simon, P. High Capacitance of Surface-Modified 2D Titanium Carbide in Acidic Electrolyte. Electrochem. Commun. 2014, 48, 118-122.

Naguib, M.; Kurtoglu, M.; Presser, V.; Lu, J.; Niu, J.; Heon, M.; Hultman, L.; Gogotsi, Y.; Barsoum, M. W. Two-Dimensional Nanocrystals Produced by Exfoliation of $\mathrm{Ti}_{3} \mathrm{AlC}_{2}$. Adv. Mater. 2011, 23, 4248-4253.

(18) Ying, Y.; Liu, Y.; Wang, X.; Mao, Y.; Cao, W.; Hu, P.; Peng, X. Two-Dimensional Titanium Carbide for Efficiently Reductive Removal of Highly Toxic Chromium(VI) from Water. ACS Appl. Mater. Interfaces 2015, 7, 1795-1803.

(19) Gao, Y.; Wang, L.; Li, Z.; Zhou, A.; Hu, Q.; Cao, X. Preparation of MXene- $\mathrm{Cu}_{2} \mathrm{O}$ Nanocomposite and Effect on Thermal Decomposition of Ammonium Perchlorate. Solid State Sci. 2014, 35, 62-65.

(20) Ren, C. E.; Zhao, M.-Q.; Makaryan, T.; Halim, J.; Boota, M.; Kota, S.; Anasori, B.; Barsoum, M. W.; Gogotsi, Y. Porous Two-Dimensional Transition Metal Carbide (MXene) Flakes for High-Performance Li-Ion Storage. ChemElectroChem 2016. doi:10.1002/celc.201600059

(21) Citrin, P. H. High-Resolution X-Ray Photoemission from Sodium Metal and Its Hydroxide. Phys. Rev. B 1973, 8, 5545-5556.

(22) Nefedov, V. I.; Salyn, Y. V.; Leonhardt, G.; Scheibe, R. A Comparison of Different Spectrometers and Charge Corrections Used in X-Ray Photoelectron Spectroscopy. J. Electron Spectrosc. Relat. Phenom. 1977, 10, $121-124$.

(23) Barrie, A.; Street, F. J. An Auger and X-Ray Photoelectron Spectroscopic Study of Sodium Metal and Sodium Oxide. J. Electron Spectrosc. Relat. Phenom. 1975, 7, $1-31$.

(24) Briggs, D.; Seah, M. P. Practical Surface Analysis, Auger and X-Ray Photoelectron Spectroscopy; Wiley, 1990.

(25) Guo, C.; Yin, S.; Dong, Q.; Sato, T. Near-Infrared Absorption Properties of $\mathrm{Rb}_{x} \mathrm{WO}_{3}$ Nanoparticles. CrystEngComm 2012, 14, 7727-7732.

(26) Norrish, K. The Swelling of Montmorillonite. Discuss Faraday Soc 1954, 18, 120-134.

(27) Hou, X.; Bish, D. L.; Wang, S.-L.; Johnston, C. T.; Kirkpatrick, R. J. Hydration, Expansion, Structure, and Dynamics of Layered Double Hydroxides. Am. Mineral. 2003, 88, 167-179.

(28) Ghidiu, M.; Naguib, M.; Shi, C.; Mashtalir, O.; Pan, L. M.; Zhang, B.; Yang, J.; Gogotsi, Y.; Billinge, S. J. L.; Barsoum, M. W. Synthesis and Characterization of Two-Dimensional $\mathrm{Nb}_{4} \mathrm{C}_{3}$ (MXene). Chem. Commun. 2014, 50, 9517-9520. 
(29) A. Lerf; R. Schöllhorn. Solvation Reactions of Layered Ternary Sulfides $\mathrm{A}_{x} \mathrm{TiS}_{2}, \mathrm{~A}_{x} \mathrm{NbS}_{2}$, and $\mathrm{A}_{x} \mathrm{TaS}_{2}$. Inorg. Chem. 1977, 16, 2950-2956.

(30) Foo, M. L.; Klimczuk, T.; Cava, R. J. Hydration Phase Diagram for Sodium Cobalt Oxide $\mathrm{Na}_{0.3} \mathrm{CoO}_{2} \cdot \mathrm{yH}_{2} \mathrm{O}$. Mater. Res. Bull. 2005, 40, 665-670.

(31) Sasaki, T.; Komatsu, Y.; Fujiki, Y. Protonated Pentatitanate: Preparation, Characterizations and Cation Intercalation. Chem. Mater. 1992, 4, 894-899.

(32) Chipera, S. J.; Carey, J. W.; Bish, D. L. ControlledHumidity XRD Analyses: Application to the Study of Smectite Expansion/Contraction. In Advances in X-ray Analysis; Plenum Press, 1997; Vol. 39, pp 713-722.

(33) Bish, D. L. Parallels and Distinctions between Clays and Zeolites. In Handbook of Clay Science; Elsevier, 2013; pp 243-345.
(34) Salles, F.; Beurroies, I.; Bildstein, O.; Jullien, M.; Raynal, J.; Denoyel, R.; Damme, H. V. A Calorimetric Study of Mesoscopic Swelling and Hydration Sequence in Solid Na-Montmorillonite. Appl. Clay Sci. 2008, 39, 186-201.

(35) Johnston, D. Ambient Temperature Phase Relations in the System $\mathrm{Na}_{1 / 3}\left(\mathrm{H}_{2} \mathrm{O}\right)_{\mathrm{y}} \mathrm{TaS}_{2}(0<\mathrm{y}<2)$. Mater. Res. Bull. 1982, 17, 13-23.

(36) H.J. Bray; S.A.T. Redfern. Kinetics of Dehydration of Ca-Montmorillonite. Phys Chem Miner. 1999, 26, 591600 .

(37) Whittingham, M. S. The Hydrated Intercalation Complexes of the Layered Disulfides. Mater. Res. Bull. 1974, 9, 1681-1689.

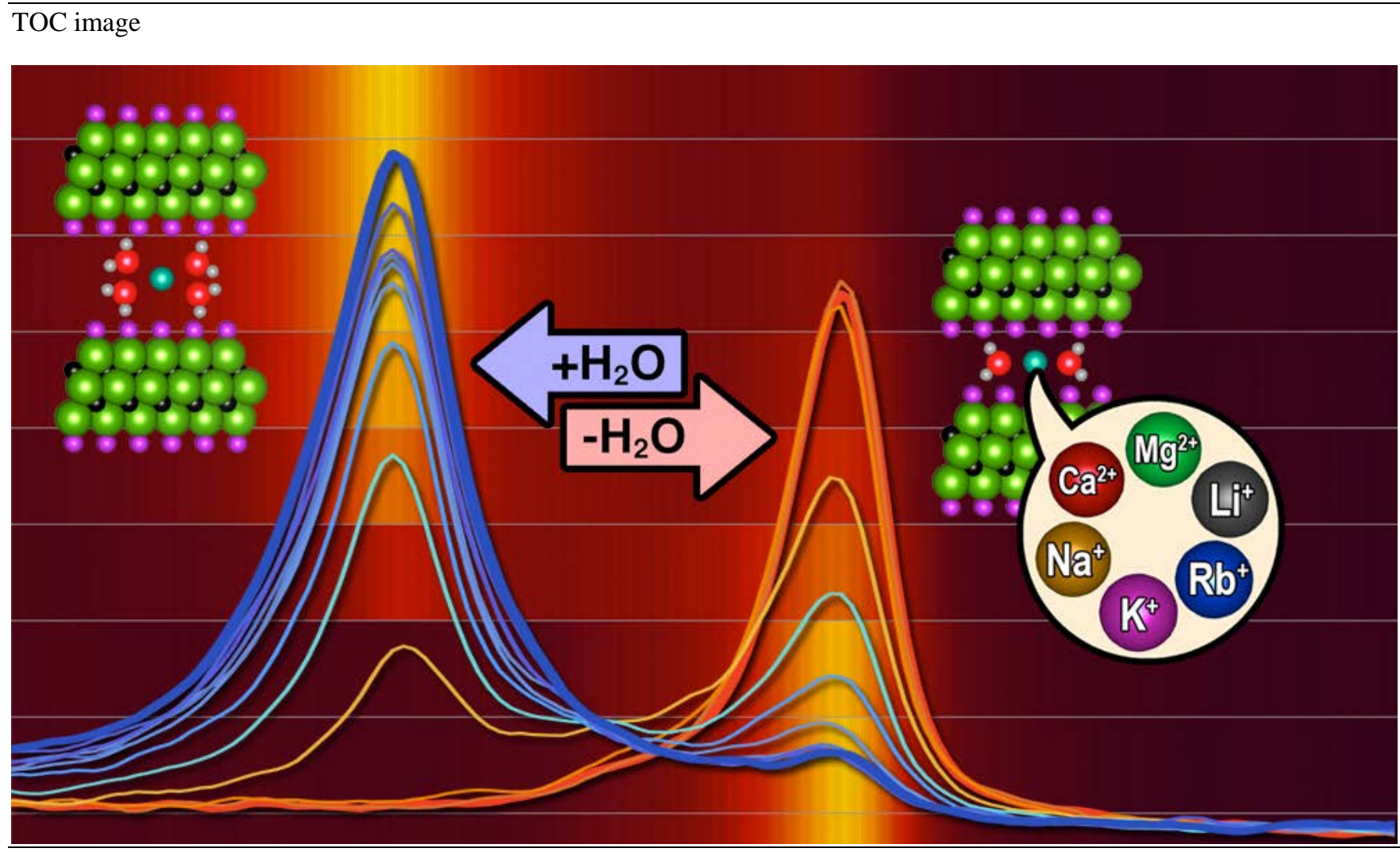




\section{Supporting Information}

\section{Ion-Exchange and Cation Solvation Reactions in $\mathrm{Ti}_{3} \mathrm{C}_{2}$ MXene}

Michael Ghidiu, ${ }^{\dagger}$ Joseph Halim, ${ }^{\dagger, \S}$ Sankalp Kota, ${ }^{\dagger}$ David Bish, ${ }^{\ddagger}$ Yury Gogotsi, ${ }^{\dagger}{ }^{\dagger}$ and Michel W. Barsoum $^{\dagger, *}$

† Department of Materials Science and Engineering, Drexel University, Philadelphia, PA 19104

${ }^{\ddagger}$ Department of Geological Sciences, Indiana University, Bloomington, IN 47405

$\S$ Thin Film Physics Division, Department of Physics, Chemistry and Biology (IFM), Linköping University, SE-58183 Linköping (Sweden)

॥ A. J. Drexel Nanomaterials Institute, Drexel University, Philadelphia, PA 19104

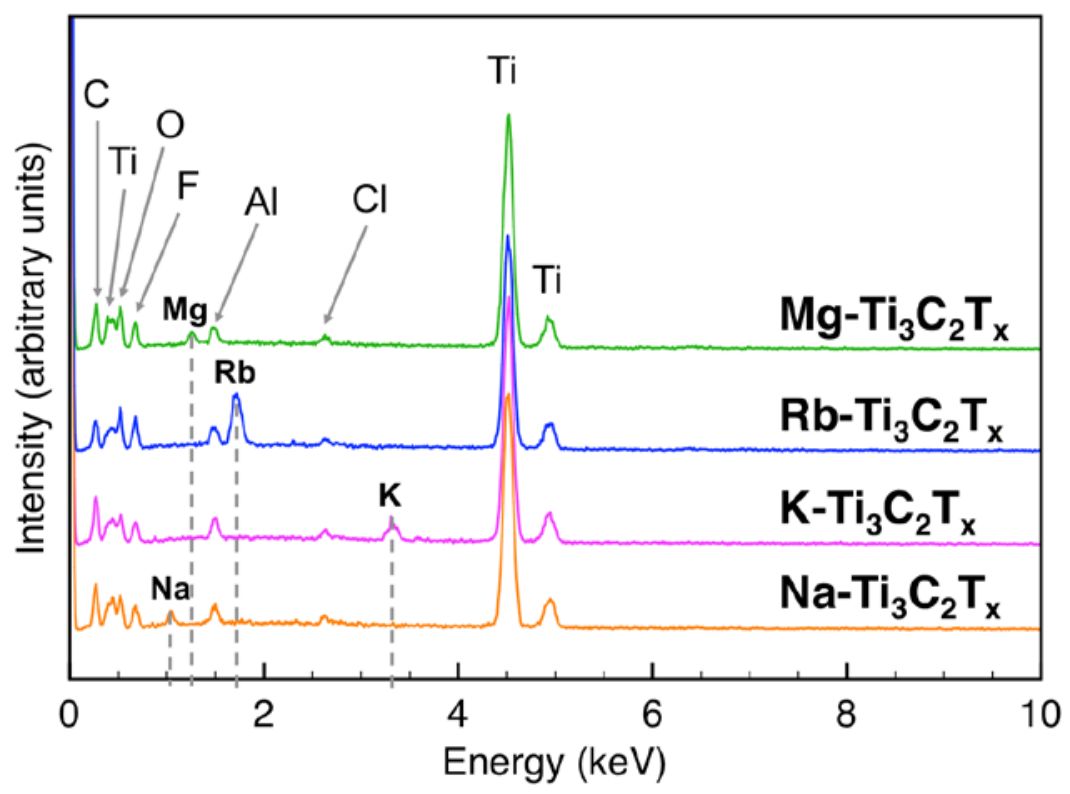

Figure S1. Energy-dispersive spectroscopy results for $\mathbf{M g}-\mathbf{T i}_{3} \mathbf{C}_{2} \mathbf{T}_{\mathbf{x}}, \mathbf{R b}-\mathbf{T i}_{3} \mathbf{C}_{2} \mathbf{T}_{\mathbf{x}}, \mathbf{K}-\mathbf{T i}_{3} \mathbf{C}_{2} \mathbf{T}_{\mathbf{x}}$, and $\mathbf{N a} \mathbf{T i}_{3} \mathrm{C}_{2} \mathbf{T}_{\mathbf{x}}$. $\mathrm{Cl}$ signal is possibly from $\mathrm{LiCl}$ used during etching.

Table S1. Energy-dispersive spectroscopy data for cation-intercalated $\mathrm{Ti}_{3} \mathrm{C}_{2} \mathrm{~T}_{\mathrm{x}}$ after acid washing and immersion in salt solutions. All values are reported in atoms per formula unit of $\mathrm{Ti}_{3} \mathrm{C}_{2}$, averaged over three sample locations at low magnification (roughly 200-500X) in the SEM.

\begin{tabular}{|c|c|c|c|c|c|c|c|c|c|c|}
\hline \multirow[b]{2}{*}{ Element } & \multicolumn{2}{|c|}{$\mathrm{Li}_{-} \mathrm{Ti}_{3} \mathrm{C}_{2} \mathrm{~T}_{\mathrm{x}}$} & \multicolumn{2}{|c|}{$\mathrm{Na}-\mathrm{Ti}_{3} \mathrm{C}_{2} \mathrm{~T}_{\mathrm{x}}$} & \multicolumn{2}{|c|}{$M g-T_{3} C_{2} T_{x}$} & \multicolumn{2}{|c|}{$\mathbf{K}-\mathbf{T i}_{3} \mathrm{C}_{2} \mathbf{T}_{\mathbf{x}}$} & \multicolumn{2}{|c|}{$\mathbf{R b}-\mathbf{T i}_{3} \mathrm{C}_{2} \mathrm{~T}_{\mathbf{x}}$} \\
\hline & Mean & $\begin{array}{l}\text { Std. } \\
\text { Dev. }^{\text {a }}\end{array}$ & Mean & $\begin{array}{c}\text { Std. } \\
\text { Dev. }^{\text {a }}\end{array}$ & Mean & $\begin{array}{l}\text { Std. } \\
\text { Dev. }^{\text {a }}\end{array}$ & Mean & $\begin{array}{l}\text { Std. } \\
\text { Dev. }^{\text {a }}\end{array}$ & Mean & $\begin{array}{c}\text { Std. } \\
\text { Dev. }^{\text {a }}\end{array}$ \\
\hline $\begin{array}{r}\text { Ti } \\
\text { Al }\end{array}$ & $\begin{array}{c}3.0 \\
0.25\end{array}$ & 0.08 & $\begin{array}{c}3.0 \\
0.11\end{array}$ & 0.00 & $\begin{array}{c}3.0 \\
0.12\end{array}$ & 0.01 & $\begin{array}{c}3.0 \\
0.13\end{array}$ & 0.00 & $\begin{array}{c}3.0 \\
0.13\end{array}$ & 0.01 \\
\hline C & 2.07 & 0.20 & 2.09 & 0.04 & 2.14 & 0.08 & 2.46 & 0.05 & 2.10 & 0.11 \\
\hline $\mathbf{O}$ & 2.24 & 0.24 & 2.07 & 0.23 & 2.81 & 0.19 & 1.99 & 0.23 & 2.48 & 0.23 \\
\hline $\mathbf{F}$ & 1.42 & 0.12 & 1.57 & 0.13 & 1.51 & 0.19 & 1.35 & 0.05 & 1.90 & 0.05 \\
\hline $\mathrm{Cl}$ & 0.05 & 0.01 & 0.06 & 0.01 & 0.06 & 0.00 & 0.05 & 0.01 & 0.07 & 0.01 \\
\hline Cation ${ }^{b}$ & -- & -- & 0.18 & 0.03 & 0.08 & 0.03 & 0.17 & 0.03 & 0.25 & 0.01 \\
\hline
\end{tabular}

a Signals from various spectra were normalized to the Ti signal, so a standard deviation is not provided for Ti.

${ }^{\mathrm{b}} \mathrm{Li}$ does not give a useful signal in EDS measurements 
Table S2. Experimental hydration enthalpies for selected cations

\begin{tabular}{cc}
\hline Cation & Hydration Enthalpy $\boldsymbol{-} \boldsymbol{A H}^{\circ}$ hyd $\left.\mathbf{( k J} / \mathbf{m o l}\right)$ \\
\hline $\mathrm{Li}^{+}$ & 519 \\
$\mathrm{Na}^{+}$ & 409 \\
$\mathrm{~K}^{+}$ & 322 \\
$\mathrm{Rb}^{+}$ & 293 \\
$\mathrm{Mg}^{2+}$ & 1921 \\
$\mathrm{Ca}^{2+}$ & 1577 \\
\hline \multicolumn{2}{c}{ All hydration enthalpy values are from Ref. 1 }
\end{tabular}

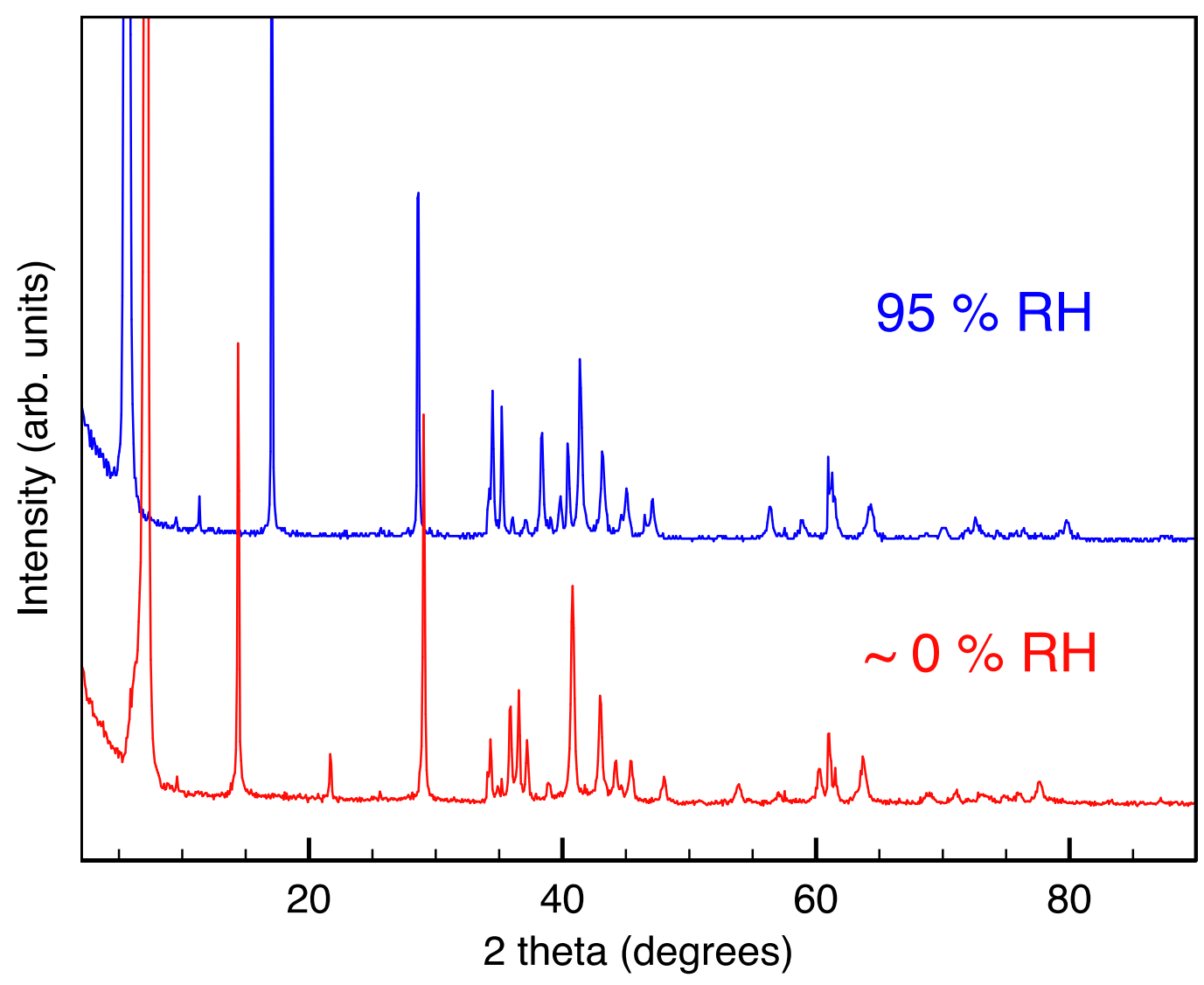

Figure S2: Full X-ray diffraction patterns of Ca- $\mathrm{Ti}_{3} \mathrm{C}_{2} \mathrm{~T}_{\mathrm{x}}$ at $95 \% \mathrm{RH}$ (bilayer $\mathrm{H}_{2} \mathrm{O}$ structure; blue trace, top) and at $\sim 0 \% \mathrm{RH}$ (monolayer $\mathrm{H}_{2} \mathrm{O}$ structure; red trace, bottom). The 002 peak intensities are truncated so that the $h k l$ regions are visible. 


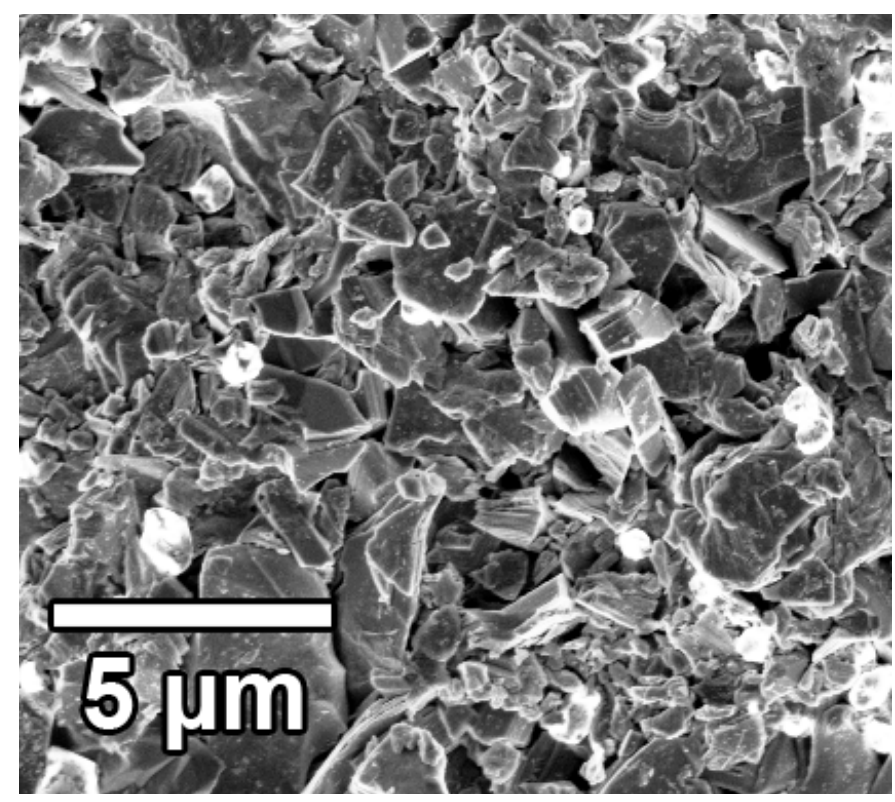

Figure S3. Scanning electron micrograph of multilayer $\mathrm{Li}_{-} \mathrm{Ti}_{3} \mathrm{C}_{2} \mathrm{~T}_{\mathrm{x}}$, showing typical particle sizes.

Table S3. Normalized mass fractions associated with $\mathrm{H}_{2} \mathrm{O}$ after TGA of various cation-intercalated $\mathrm{Ti}_{3} \mathrm{C}_{2} \mathrm{~T}_{\mathrm{x}}$.

\begin{tabular}{cccc}
\hline sample & wt fraction $_{\text {total }}{ }^{\text {a }}$ & wt fraction $_{\text {ion }}{ }^{\text {b }}$ & wt fraction $_{\text {non-ion }}{ }^{\mathbf{c}}$ \\
\hline $\mathbf{K}-\mathrm{Ti}_{3} \mathrm{C}_{2} \mathrm{~T}_{\mathrm{x}}$ & 1.04 & 0.02 & 0.025 \\
$\mathbf{N a}-\mathrm{Ti}_{3} \mathrm{C}_{2} \mathrm{~T}_{\mathrm{x}}$ & 1.05 & 0.02 & 0.025 \\
$\mathbf{L i}-\mathrm{Ti}_{3} \mathrm{C}_{2} \mathrm{~T}_{\mathrm{x}}$ & 1.05 & 0.03 & 0.025 \\
$\mathbf{C a}-\mathrm{Ti}_{3} \mathrm{C}_{2} \mathrm{~T}_{\mathrm{x}}$ & 1.10 & 0.08 & 0.025 \\
\hline
\end{tabular}

${ }^{a}$ From TGA data after normalization to the mass $\%$ after $120^{\circ} \mathrm{C}$.

${ }^{b}$ Normalized mass \% from region with dependence on cation hydration enthalpy, green area in Fig. 6b. 1.025 was chosen as the end of this region as it was the shared y-intercept of the linear fits of the first two sets of data (initial and after 27 $\left.{ }^{\circ} \mathrm{C}\right)$.

${ }^{\mathrm{c}}$ Normalized mass \% from region between 1.0 and cation-dependent region, red area in Fig. 6b.

Table S4. $\mathrm{H}_{2} \mathrm{O}$ associated with cations in the unit cell

\begin{tabular}{|c|c|c|c|c|}
\hline & $\begin{array}{c}\text { molar mass } \\
\text { MXene + cation } \\
\left(\mathrm{g} \mathrm{mol}^{-1}\right)^{\mathrm{a}}\end{array}$ & $\begin{array}{c}\text { mmol ion- } \\
\text { associated } \mathrm{H}_{2} \mathrm{O}^{\mathrm{b}}\end{array}$ & $\begin{array}{l}\operatorname{mmol} A- \\
\mathrm{Ti}_{3} C_{2} T_{x}{ }^{c}\end{array}$ & $\begin{array}{c}\# \mathrm{H}_{2} \mathrm{O} / \mathrm{Ti}_{3} \mathrm{C}_{2} \\
\text { (ion-associated) }\end{array}$ \\
\hline $\mathbf{K}-\mathrm{Ti}_{3} \mathrm{C}_{2} \mathrm{~T}_{\mathrm{x}}$ & 208.2 & 0.9 & 4.8 & 0.18 \\
\hline $\mathbf{N a}-\mathrm{Ti}_{3} \mathrm{C}_{2} \mathrm{~T}_{\mathrm{X}}$ & 211.5 & 1.1 & 4.7 & 0.24 \\
\hline $\mathbf{L i}-\mathrm{Ti}_{3} \mathrm{C}_{2} \mathrm{~T}_{\mathrm{x}}$ & 205.0 & 1.4 & 4.9 & 0.29 \\
\hline $\mathbf{C a}-\mathrm{Ti}_{3} \mathrm{C}_{2} \mathrm{~T}_{\mathrm{x}}$ & 207.6 & 4.4 & 4.8 & 0.91 \\
\hline
\end{tabular}

a Calculated from representative formula $\mathrm{M}_{y} \mathrm{Ti}_{3} \mathrm{C}_{2}(\mathrm{OH}) \mathrm{F}$, where $\mathrm{M}$ is a cation and $y$ is assumed to be 0.2 for monovalent cations and 0.1 for divalent cations. This formula is assumed for dry MXene after dehydration at $120^{\circ} \mathrm{C}$.

${ }^{\mathrm{b}}$ per $1 \mathrm{~g}$ total: $\{$ wt fraction $i o n\} *\{1 \mathrm{~g}\} / 18.02 \mathrm{~g} \mathrm{~mol}^{-1}$

c per $1 \mathrm{~g}$ total: $\{$ wt fraction of 1.0$\} *\{1 \mathrm{~g}\} / \mathrm{MW}\{$ MXene + cation $\}\left(\mathrm{g} \mathrm{mol}^{-1}\right.$ ) 


\section{$\underline{\mathrm{X} \text {-ray photoelectron spectroscopy data }}$}

Table S5: Summary of global atomic percentages before and after sputtering

\begin{tabular}{|c|c|c|c|c|c|c|c|c|c|}
\hline & Ti at. $\%$ & $\mathrm{C}$ at. $\%$ & O at. $\%$ & F at. $\%$ & Al at. $\%$ & Li at. $\%$ & Rb at. $\%$ & Na at. $\%$ & $\mathrm{Cl}$ at. $\%$ \\
\hline $\begin{array}{c}\mathbf{T i}_{3} \mathbf{C}_{2} \mathbf{T}_{\mathbf{x}} \mathbf{H F 1 0} \\
\text { before sputtering }\end{array}$ & $29.1 \pm 0.1$ & $34.5 \pm 0.6$ & $21.9 \pm 0.1$ & $13.9 \pm 0.1$ & $0.6 \pm 0.1$ & -- & -- & & -- \\
\hline $\begin{array}{l}\mathbf{T i}_{3} \mathbf{C}_{2} \mathbf{T}_{\mathbf{x}} \mathbf{H F 1 0} \\
\text { after sputtering }\end{array}$ & $38.6 \pm 0.1$ & $25.5 \pm 0.6$ & $24.9 \pm 0.2$ & $9.5 . \pm 0.1$ & $1.5 \pm 0.1$ & -- & -- & & -- \\
\hline $\begin{array}{c}\mathbf{L i}-\mathbf{T i}_{3} \mathbf{C}_{2} \mathbf{T}_{\mathbf{x}} \text { before } \\
\text { sputtering }\end{array}$ & $25.0 \pm 0.2$ & $36.4 \pm 0.5$ & $22.0 \pm 0.5$ & $10.9 \pm 0.4$ & $0.6 \pm 0.1$ & $5.7 \pm 0.3$ & -- & & $0.7 \pm 0.2$ \\
\hline $\begin{array}{c}\mathbf{L i}-\mathbf{T i}_{3} \mathbf{C}_{2} \mathbf{T}_{\mathbf{x}} \text { after } \\
\text { sputtering }\end{array}$ & $38.4 \pm 0.1$ & $22.2 \pm 0.2$ & $26.4 \pm 0.2$ & $7.9 \pm 0.2$ & $1.3 \pm 0.1$ & $3.3 \pm 0.2$ & -- & & $0.5 \pm 0.1$ \\
\hline $\begin{array}{c}\mathbf{N a}-\mathbf{T i}_{3} \mathbf{C}_{2} \mathbf{T}_{\mathbf{x}} \\
\text { before sputtering }\end{array}$ & $21.2 \pm 0.1$ & $30.9 \pm 0.1$ & $24.4 \pm 0.2$ & $11.5 \pm 0.1$ & $1.2 \pm 0.1$ & $4.3 \pm 0.2$ & -- & $5.9 \pm 0.1$ & $0.6 \pm 0.1$ \\
\hline $\begin{array}{c}\mathbf{N a}-\mathbf{T i}_{3} \mathbf{C}_{2} \mathbf{T}_{\mathbf{x}} \text { after } \\
\text { sputtering }\end{array}$ & $38.3 \pm 0.3$ & $20.6 \pm 0.2$ & $24.6 \pm 0.1$ & $7.0 \pm 0.3$ & $1.4 \pm 0.1$ & $3.7 \pm 0.2$ & -- & $3.7 \pm 0.1$ & $0.7 \pm 0.1$ \\
\hline $\begin{array}{c}\mathbf{R b}-\mathbf{T i}_{3} \mathbf{C}_{2} \mathbf{T}_{\mathbf{x}} \\
\text { before sputtering }\end{array}$ & $27.2 \pm 0.2$ & $34.0 \pm 0.3$ & 23.3. \pm 0.3 & $7.9 \pm 0.2$ & $1.6 \pm 0.2$ & $4.2 \pm 0.4$ & $1.2 \pm 0.2$ & & $0.7 \pm 0.2$ \\
\hline $\begin{array}{c}\mathbf{R b}-\mathbf{T i}_{3} \mathbf{C}_{2} \mathbf{T}_{\mathbf{x}} \text { after } \\
\text { sputtering }\end{array}$ & $32.6 \pm 0.1$ & $20.0 \pm 0.3$ & $34.6 \pm 0.6$ & $5.7 \pm 0.1$ & $1.6 \pm 0.3$ & -- & $1.1 \pm 0.2$ & & $0.5 \pm 0.3$ \\
\hline
\end{tabular}

Table S6: Summary of moieties assumed to exist in MXenes.

\begin{tabular}{cl}
\hline Moiety & \multicolumn{1}{c}{ Refers to } \\
\hline I & $\mathrm{Ti}_{3} \mathrm{C}_{2} \mathrm{O}_{\mathrm{x}}(\mathrm{MX}$ Xene terminated with oxygen) \\
II & $\mathrm{Ti}_{3} \mathrm{C}_{2}(\mathrm{OH})_{\mathrm{x}}$ (MXene terminated with hydroxyl group) \\
III & $\mathrm{Ti}_{3} \mathrm{C}_{2} \mathrm{~F}_{\mathrm{x}}(\mathrm{MXene}$ terminated with fluorine $)$ \\
IV & $\mathrm{Ti}_{3} \mathrm{C}_{2}(\mathrm{OH})_{\mathrm{x}}-\mathrm{H}_{2} \mathrm{O}\left(\mathrm{H}_{2} \mathrm{O}\right.$ adsorbed on the hydroxyl group termination) \\
\hline
\end{tabular}

Table S7: Summary of the chemical formula for various $\mathrm{Ti}_{3} \mathrm{C}_{2}$ samples.

\begin{tabular}{|c|c|}
\hline Sample & Formula \\
\hline $\mathrm{Ti}_{3} \mathrm{C}_{2} \mathrm{~T}_{\mathrm{x}} \mathrm{HF10}$ before sputtering & $\mathrm{Ti}_{3} \mathrm{C}_{2} \mathrm{O}_{0.5}(\mathrm{OH})_{0.16}\left(\mathrm{OH}-\mathrm{H}_{2} \mathrm{O}\right)_{0.3} \mathrm{~F}_{1}$ \\
\hline $\mathrm{Ti}_{3} \mathrm{C}_{2} \mathrm{~T}_{\mathrm{x}} \mathrm{HF10}$ after sputtering & $\mathrm{Ti}_{3} \mathrm{C}_{1.7} \mathrm{O}_{1}(\mathrm{OH})_{0.3}\left(\mathrm{OH}-\mathrm{H}_{2} \mathrm{O}\right)_{0.2} \mathrm{~F}_{0.3}$ \\
\hline 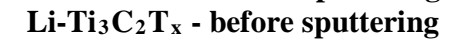 & $\mathrm{Ti}_{3} \mathrm{C}_{2} \mathrm{O}_{0.6}(\mathrm{OH})_{0.08}\left(\mathrm{OH}-\mathrm{H}_{2} \mathrm{O}\right)_{0.4} \mathrm{~F}_{0.8}-0.3 \mathrm{Li}$ \\
\hline $\mathrm{Li}_{-} \mathrm{Ti}_{3} \mathrm{C}_{2} \mathrm{~T}_{\mathrm{x}}$ after sputtering & $\mathrm{Ti}_{3} \mathrm{C}_{1.7} \mathrm{O}_{1}(\mathrm{OH})_{0.1}\left(\mathrm{OH}-\mathrm{H}_{2} \mathrm{O}\right)_{0.3} \mathrm{~F}_{0.3}-0.1 \mathrm{Li}$ \\
\hline $\mathrm{Na}-\mathrm{Ti}_{3} \mathrm{C}_{2} \mathrm{~T}_{\mathrm{x}}$ - before sputtering & $\mathrm{Ti}_{3} \mathrm{C}_{2} \mathrm{O}_{0.6}(\mathrm{OH})_{0.1}\left(\mathrm{OH}-\mathrm{H}_{2} \mathrm{O}\right)_{0.7} \mathrm{~F}_{0.6}-0.24 \mathrm{Na}$ \\
\hline $\mathrm{Na}-\mathrm{Ti}_{3} \mathrm{C}_{2} \mathrm{~T}_{\mathrm{x}}$ after sputtering & $\mathrm{Ti}_{3} \mathrm{C}_{1.6} \mathrm{O}_{1.0}(\mathrm{OH})_{0.2}\left(\mathrm{OH}-\mathrm{H}_{2} \mathrm{O}\right)_{0.3} \mathrm{~F}_{0.3}-0.1 \mathrm{Na}$ \\
\hline$R \mathbf{R b}-\mathrm{Ti}_{3} \mathrm{C}_{2} \mathrm{~T}_{\mathrm{x}}$ - before sputtering & $\mathrm{Ti}_{3} \mathrm{C}_{2} \mathrm{O}_{0.5}(\mathrm{OH})_{0.1}\left(\mathrm{OH}-\mathrm{H}_{2} \mathrm{O}\right)_{0.5} \mathrm{~F}_{0.7}-0.16 \mathrm{Rb}$ \\
\hline $\mathbf{R b}-\mathrm{Ti}_{3} \mathrm{C}_{2} \mathrm{~T}_{\mathrm{x}}$ after sputtering & $\mathrm{Ti}_{3} \mathrm{C}_{1.5} \mathrm{O}_{1.0}(\mathrm{OH})_{0.6}\left(\mathrm{OH}-\mathrm{H}_{2} \mathrm{O}\right)_{0.4} \mathrm{~F}_{0.2}-0.11 \mathrm{Rb}$ \\
\hline
\end{tabular}




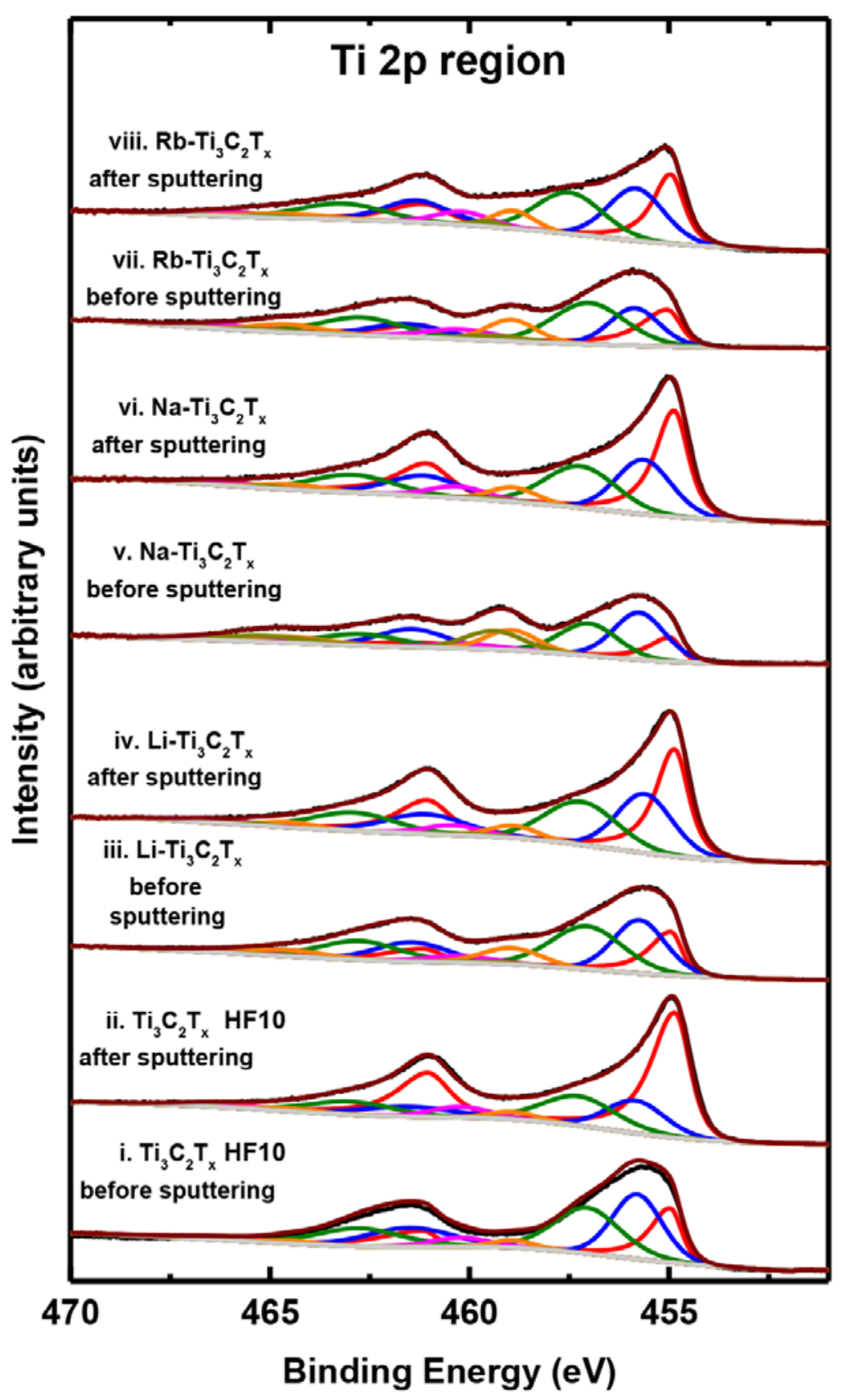

Figure S4. XPS spectra with curve-fitting for Ti 2p region for (i) $\mathrm{Ti}_{3} \mathrm{C}_{2} \mathrm{~T}_{\mathrm{x}}$ HF10 before sputtering; (ii) $\mathrm{Ti}_{3} \mathrm{C}_{2} \mathrm{~T}_{\mathrm{x}}$

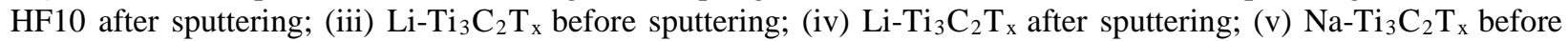
sputtering; (vi) Na-Ti ${ }_{3} \mathrm{C}_{2} \mathrm{~T}_{\mathrm{x}}$ after sputtering; (vii) $\mathrm{Rb}-\mathrm{Ti}_{3} \mathrm{C}_{2} \mathrm{~T}_{\mathrm{x}}$ before sputtering; and (viii) $\mathrm{Rb}-\mathrm{Ti}_{3} \mathrm{C}_{2} \mathrm{~T}_{\mathrm{x}}$ after sputtering. Table S8 identifies and quantifies the various components shown. 
Table S8: XPS peak fitting results for Ti $2 p$ region of various $\mathrm{Ti}_{3} \mathrm{C}_{2} \mathrm{~T}_{\mathrm{x}}$ MXenes before and after sputtering.

\begin{tabular}{|c|c|c|c|c|c|}
\hline Sample & $\mathrm{BE}[\mathrm{eV}]^{\mathrm{a}}$ & $\begin{array}{c}\text { FWHM } \\
\text { [eV] }^{\mathbf{a}}\end{array}$ & Fraction & Assigned to & Reference \\
\hline \multirow{6}{*}{$\begin{array}{l}\mathbf{T i}_{3} \mathbf{C}_{2} \mathbf{T}_{\mathbf{x}} \mathbf{H F 1 0} \text {, } \\
\text { before sputtering }\end{array}$} & 455.0 (461.2) & $0.7(0.9)$ & 0.22 & Ti (I, II or IV) & 2 \\
\hline & 455.8 (461.5) & $1.5(2.5)$ & 0.34 & $\mathrm{Ti}+2$ (I, II, or IV) & 2 \\
\hline & 457.1 (462.8) & $2.0(2.5)$ & 0.33 & $\mathrm{Ti}+3$ (I, II, or IV) & 2 \\
\hline & $458.9(464.5)$ & $1.2(1.4)$ & 0.03 & $\mathrm{TiO}_{2}$ & 3,4 \\
\hline & 459.2 (464.9) & $1.8(2.7)$ & 0.02 & $\mathrm{TiO}_{2-\mathrm{x}} \mathrm{F}_{\mathrm{x}}$ & 5 \\
\hline & $460.2(466.2)$ & $1.7(2.7)$ & 0.07 & C-Ti-F (III) & 2 \\
\hline \multirow{6}{*}{$\begin{array}{l}\mathbf{T i}_{3} \mathbf{C}_{2} \mathbf{T}_{\mathbf{x}} \mathbf{H F 1 0} \text {, } \\
\text { after sputtering }\end{array}$} & 454.9 (461.1) & $0.9(1.3)$ & 0.51 & Ti (I, II or IV) & 2 \\
\hline & 455.8 (461.5) & $1.7(2.8)$ & 0.19 & $\mathrm{Ti}+2$ (I, II, or IV) & 2 \\
\hline & 457.2 (462.9) & $2.2(2.5)$ & 0.21 & $\mathrm{Ti}+3$ (I, II, or IV) & 2 \\
\hline & 458.9 (464.5) & $1.3(1.9)$ & 0.02 & $\mathrm{TiO}_{2}$ & 3,4 \\
\hline & $459.2(464.9)$ & $1.7(2.0)$ & 0.01 & $\mathrm{TiO}_{2-\mathrm{x}} \mathrm{F}_{\mathrm{x}}$ & 5 \\
\hline & $460.2(466.2)$ & $1.8(2.5)$ & 0.06 & $\mathrm{C}-\mathrm{Ti}-\mathrm{F}_{\mathrm{x}}$ (III) & 2 \\
\hline \multirow{6}{*}{$\begin{array}{l}\mathbf{L i}-\mathbf{T i}_{3} \mathbf{C}_{2} \mathbf{T}_{\mathbf{x}} \text {, } \\
\text { before sputtering }\end{array}$} & $455.0(461.2)$ & $0.7(1.0)$ & 0.20 & Ti (I, II or IV) & 2 \\
\hline & $455.8(461.4)$ & $1.5(2.4)$ & 0.34 & $\mathrm{Ti}+2$ (I, II, or IV) & 2 \\
\hline & 457.1 (462.8) & $2.1(2.5)$ & 0.32 & Ti+3 (I, II, or IV) & 2 \\
\hline & $459.0(464.6)$ & $1.3(2.5)$ & 0.04 & $\mathrm{TiO}_{2}$ & 3,4 \\
\hline & $459.2(464.9)$ & $1.8(2.7)$ & 0.03 & $\mathrm{TiO}_{2-\mathrm{x}} \mathrm{F}_{\mathrm{x}}$ & 5 \\
\hline & $460.2(466.2)$ & $1.9(2.7)$ & 0.07 & $\mathrm{C}-\mathrm{Ti}-\mathrm{F}_{\mathrm{x}}$ (III) & 2 \\
\hline \multirow{6}{*}{$\begin{array}{l}\mathbf{L i}-\mathbf{T i} \mathbf{i}_{3} \mathbf{C}_{2} \mathbf{T}_{\mathbf{x}} \text {, } \\
\text { after sputtering }\end{array}$} & 454.9 (461.1) & $0.9(1.3)$ & 0.45 & Ti (I, II or IV) & 2 \\
\hline & 455.7 (461.4) & $1.6(2.5)$ & 0.20 & $\mathrm{Ti}+2$ (I, II, or IV) & 2 \\
\hline & $457.2(462.9)$ & $2.1(2.6)$ & 0.24 & $\mathrm{Ti}+3$ (I, II, or IV) & 2 \\
\hline & 458.9 (464.5) & $1.4(2.0)$ & 0.03 & $\mathrm{TiO}_{2}$ & 3,4 \\
\hline & $459.3(464.8)$ & $1.7(2.0)$ & 0.01 & $\mathrm{TiO}_{2-\mathrm{x}} \mathrm{F}_{\mathrm{x}}$ & 5 \\
\hline & $460.2(466.2)$ & $1.7(2.6)$ & 0.07 & $\mathrm{C}-\mathrm{Ti}-\mathrm{F}_{\mathrm{x}}$ (III) & 2 \\
\hline \multirow{6}{*}{$\begin{array}{l}\mathbf{N a -} \mathbf{T i}_{3} \mathbf{C}_{2} \mathbf{T}_{\mathbf{x}} \text {, } \\
\text { before sputtering }\end{array}$} & $455.0(461.2)$ & $0.7(1.7)$ & 0.12 & Ti (I, II or IV) & 2 \\
\hline & 455.7 (461.4) & $1.5(2.0)$ & 0.32 & $\mathrm{Ti}+2$ (I, II, or IV) & 2 \\
\hline & $457.0(462.7)$ & $1.7(2.4)$ & 0.24 & $\mathrm{Ti}+3$ (I, II, or IV) & 2 \\
\hline & $459.0(464.6)$ & $1.5(2.4)$ & 0.13 & $\mathrm{TiO}_{2}$ & 3,4 \\
\hline & 459.4 (465.1) & $1.7(2.7)$ & 0.14 & $\mathrm{TiO}_{2-\mathrm{x}} \mathrm{F}_{\mathrm{x}}$ & 5 \\
\hline & $460.2(466.2)$ & $2.0(2.7)$ & 0.05 & C-Ti-F (III) & 2 \\
\hline \multirow{6}{*}{$\begin{array}{l}\mathbf{N a -}-\mathbf{T i}_{3} \mathbf{C}_{2} \mathbf{T}_{\mathbf{x}} \text {, } \\
\text { after sputtering }\end{array}$} & 454.9 (461.1) & $0.8(1.4)$ & 0.37 & Ti (I, II or IV) & 2 \\
\hline & 455.6 (461.1) & $1.6(2.1)$ & 0.25 & Ti+2 (I, II, or IV) & 2 \\
\hline & $457.2(462.9)$ & $2.1(2.4)$ & 0.25 & $\mathrm{Ti}+3$ (I, II, or IV) & 2 \\
\hline & 458.9 (464.5) & $1.4(1.8)$ & 0.06 & $\mathrm{TiO}_{2}$ & 3,4 \\
\hline & $459.6(465.1)$ & $2.0(2.0)$ & 0.01 & $\mathrm{TiO}_{2-\mathrm{x}} \mathrm{F}_{\mathrm{x}}$ & 5 \\
\hline & $460.3(466.3)$ & $1.7(2.0)$ & 0.06 & C-Ti-F ${ }_{x}$ (III) & 2 \\
\hline \multirow{6}{*}{$\begin{array}{l}\mathbf{R b}-\mathbf{T} \mathbf{i}_{3} \mathbf{C}_{2} \mathbf{T}_{\mathbf{x}} \text {, } \\
\text { before sputtering }\end{array}$} & $455.0(461.2)$ & $0.8(1.2)$ & 0.21 & Ti (I, II or IV) & 2 \\
\hline & 455.9 (461.6) & $1.5(2.2)$ & 0.21 & $\mathrm{Ti}+2$ (I, II, or IV) & 2 \\
\hline & $457.0(462.7)$ & $2.1(2.4)$ & 0.34 & $\mathrm{Ti}+3$ (I, II, or IV) & 2 \\
\hline & 458.9 (464.5) & $1.2(2.5)$ & 0.07 & $\mathrm{TiO}_{2}$ & 3,4 \\
\hline & $459.6(465.1)$ & $0.8(1.2)$ & 0.10 & $\mathrm{TiO}_{2-\mathrm{x}} \mathrm{F}_{\mathrm{x}}$ & 5 \\
\hline & $460.2(466.2)$ & $1.6(2.1)$ & 0.07 & C-Ti-F ${ }_{x}$ (III) & 2 \\
\hline \multirow{6}{*}{$\begin{array}{l}\mathbf{R b} \mathbf{b}-\mathbf{T i}_{3} \mathbf{C}_{2} \mathbf{T}_{\mathbf{x}} \text {, } \\
\text { after sputtering }\end{array}$} & $455.0(461.2)$ & $0.8(1.5)$ & 0.27 & $\mathrm{Ti}(\mathrm{I}, \mathrm{II}$ or IV) & 2 \\
\hline & 455.8 (461.3) & $1.7(2.0)$ & 0.29 & $\mathrm{Ti}+2$ (I, II, or IV) & 2 \\
\hline & 457.5 (463.2) & $2.0(2.5)$ & 0.27 & $\mathrm{Ti}+3$ (I, II, or IV) & 2 \\
\hline & $458.9(464.5)$ & $1.2(2.5)$ & 0.07 & $\mathrm{TiO}_{2}$ & 3,4 \\
\hline & $459.3(464.8)$ & $0.8(1.2)$ & 0.02 & $\mathrm{TiO}_{2-\mathrm{x}} \mathrm{F}_{\mathrm{x}}$ & 5 \\
\hline & $460.2(466.2)$ & $1.6(2.1)$ & 0.08 & $\mathrm{C}-\mathrm{Ti}-\mathrm{F}_{\mathrm{x}}(\mathrm{III})$ & 2 \\
\hline
\end{tabular}

${ }^{\mathrm{a}}$ Values in parentheses correspond to the $2 \mathrm{p}_{1 / 2}$ component. 


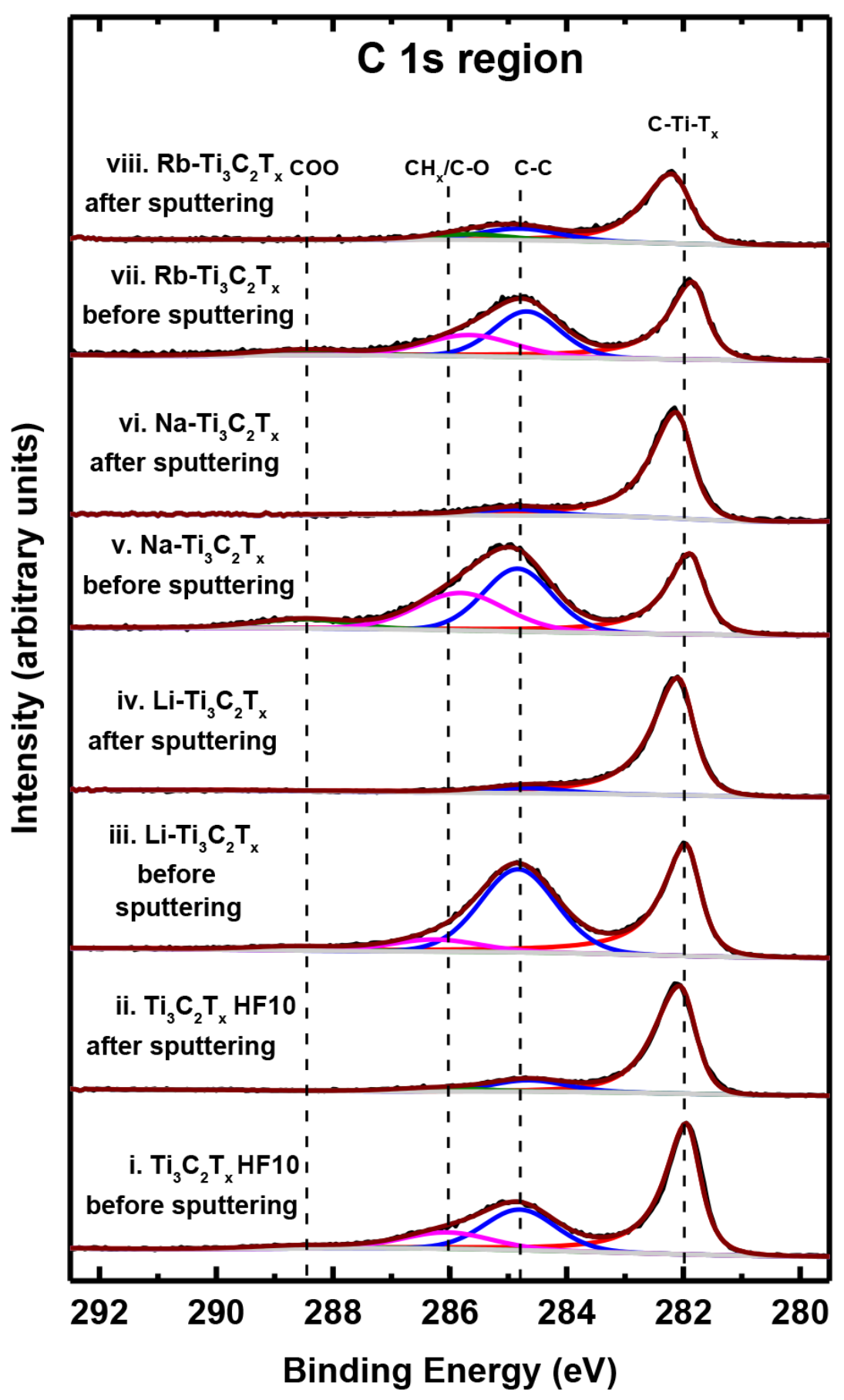

Figure S5. XPS spectra with curve-fitting for C 1s region for (i) $\mathrm{Ti}_{3} \mathrm{C}_{2} \mathrm{~T}_{\mathrm{x}}$ HF10 before sputtering; (ii) $\mathrm{Ti}_{3} \mathrm{C}_{2} \mathrm{~T}_{\mathrm{x}}$

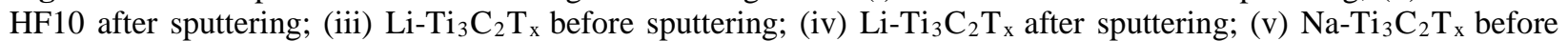
sputtering; (vi) $\mathrm{Na}_{-} \mathrm{Ti}_{3} \mathrm{C}_{2} \mathrm{~T}_{\mathrm{x}}$ after sputtering; (vii) $\mathrm{Rb}-\mathrm{Ti}_{3} \mathrm{C}_{2} \mathrm{~T}_{\mathrm{x}}$ before sputtering; and (viii) $\mathrm{Rb}-\mathrm{Ti}_{3} \mathrm{C}_{2} \mathrm{~T}_{\mathrm{x}}$ after sputtering. Dashed vertical lines, from left to right, represent the species COO (due to organic contamination), $\mathrm{CH}_{\mathrm{x}} / \mathrm{C}-\mathrm{O}$ (due to organic contamination), C-C (due to surface contamination), and C-Ti-Tx (carbon species in MXene). Table S9 identifies and quantifies the various components shown. 
Table S9: XPS peak fitting results for $\mathrm{C} 1 \mathrm{~s}$ region of various $\mathrm{Ti}_{3} \mathrm{C}_{2} \mathrm{~T}_{\mathrm{x}}$ before and after sputtering.

\begin{tabular}{|c|c|c|c|c|c|}
\hline Sample & BE [eV] & FWHM [eV] & Fraction & $\begin{array}{l}\text { Assigned to } \\
\end{array}$ & Reference \\
\hline \multirow{4}{*}{$\begin{array}{l}\mathbf{T i}_{3} \mathbf{C}_{2} \mathbf{T}_{\mathbf{x}} \mathbf{H F 1 0} \text {, } \\
\text { before sputtering }\end{array}$} & 282.0 & 0.6 & 0.58 & C-Ti-Tx $(\mathrm{I}, \mathrm{II}, \mathrm{III}$, or IV) & 2 \\
\hline & 284.8 & 1.4 & 0.27 & C-C & 6 \\
\hline & 286.0 & 1.8 & 0.13 & $\mathrm{CH}_{\mathrm{x}} / \mathrm{C}-\mathrm{O}$ & 6 \\
\hline & 288.6 & 1.8 & 0.02 & $\mathrm{C}-\mathrm{O}$ & 6 \\
\hline \multirow{3}{*}{$\begin{array}{l}\mathbf{T i}_{3} \mathbf{C}_{2} \mathbf{T}_{\mathbf{x}} \mathbf{H F 1 0} \text {, } \\
\text { after sputtering }\end{array}$} & 282.0 & 0.6 & 0.82 & C-Ti-T $x$ (I, II,III, or IV) & 2 \\
\hline & 284.8 & 1.5 & 0.13 & C-C & 6 \\
\hline & 286.4 & 1.8 & 0.05 & $\mathrm{CH}_{\mathrm{x}} / \mathrm{C}-\mathrm{O}$ & 6 \\
\hline \multirow{4}{*}{$\begin{array}{l}\mathbf{L i}-\mathbf{T i} \mathbf{i}_{3} \mathbf{C}_{2} \mathbf{T}_{\mathbf{x}} \text {, } \\
\text { before sputtering }\end{array}$} & 282.0 & 0.6 & 0.44 & C-Ti-Tx $(\mathrm{I}, \mathrm{II}, \mathrm{III}$, or IV) & 2 \\
\hline & 284.8 & 1.5 & 0.46 & $\mathrm{C}-\mathrm{C}$ & 6 \\
\hline & 286.0 & 1.8 & 0.08 & $\mathrm{CH}_{\mathrm{x}} / \mathrm{C}-\mathrm{O}$ & 6 \\
\hline & 288.6 & 1.8 & 0.02 & $\mathrm{COO}$ & 6 \\
\hline \multirow{2}{*}{$\begin{array}{l}\mathbf{L i}-\mathbf{T i}_{3} \mathbf{C}_{2} \mathbf{T}_{\mathbf{x}} \text {, } \\
\text { after sputtering }\end{array}$} & 282.1 & 0.6 & 0.95 & C-Ti-Tx $(\mathrm{I}, \mathrm{II}, \mathrm{III}$, or IV) & 2 \\
\hline & 284.7 & 1.5 & 0.5 & C-C & 6 \\
\hline \multirow{4}{*}{$\begin{array}{l}\mathbf{N a - T i} \mathbf{i}_{3} \mathbf{C}_{2} \mathbf{T}_{\mathbf{x}} \text {, } \\
\text { before sputtering }\end{array}$} & 281.9 & 0.6 & 0.35 & C-Ti-Tx $(\mathrm{I}, \mathrm{II}, \mathrm{III}$, or IV) & 2 \\
\hline & 284.8 & 1.4 & 0.33 & $\mathrm{C}-\mathrm{C}$ & 6 \\
\hline & 285.8 & 1.8 & 0.26 & $\mathrm{CH}_{\mathrm{x}} / \mathrm{C}-\mathrm{O}$ & 6 \\
\hline & 288.5 & 1.8 & 0.06 & COO & 6 \\
\hline \multirow{2}{*}{$\begin{array}{l}\mathbf{N a -} \mathbf{T i}_{3} \mathbf{C}_{2} \mathbf{T}_{\mathbf{x}}, \\
\text { after sputtering }\end{array}$} & 282.1 & 0.6 & 0.93 & C-Ti-Tx (I, II,III, or IV) & 2 \\
\hline & 284.9 & 1.3 & 0.07 & C-C & 6 \\
\hline \multirow{4}{*}{$\begin{array}{l}\mathbf{R b} \mathbf{b} \mathbf{T i}_{3} \mathbf{C}_{\mathbf{2}} \mathbf{T}_{\mathbf{x}} \text {, } \\
\text { before sputtering }\end{array}$} & 281.8 & 0.6 & 0.44 & $\mathrm{C}^{-T i}-\mathrm{T}_{\mathrm{x}}(\mathrm{I}, \mathrm{II}, \mathrm{III}$, or IV) & 2 \\
\hline & 284.7 & 1.3 & 0.31 & $\mathrm{C}-\mathrm{C}$ & 6 \\
\hline & 285.7 & 1.8 & 0.20 & $\mathrm{CH}_{\mathrm{x}} / \mathrm{C}-\mathrm{O}$ & 6 \\
\hline & 288.5 & 1.8 & 0.05 & $\mathrm{COO}$ & 6 \\
\hline \multirow{3}{*}{$\begin{array}{l}\mathbf{R b}-\mathbf{T i}_{3} \mathbf{C}_{2} \mathbf{T}_{\mathbf{x}}, \\
\text { after sputtering }\end{array}$} & 282.2 & 0.8 & 0.74 & C-Ti-Tx (I, II,III, or IV) & 2 \\
\hline & 284.8 & 1.6 & 0.18 & C-C & 6 \\
\hline & 286.4 & 1.5 & 0.08 & $\mathrm{CH}_{\mathrm{x}} / \mathrm{C}-\mathrm{O}$ & 6 \\
\hline
\end{tabular}




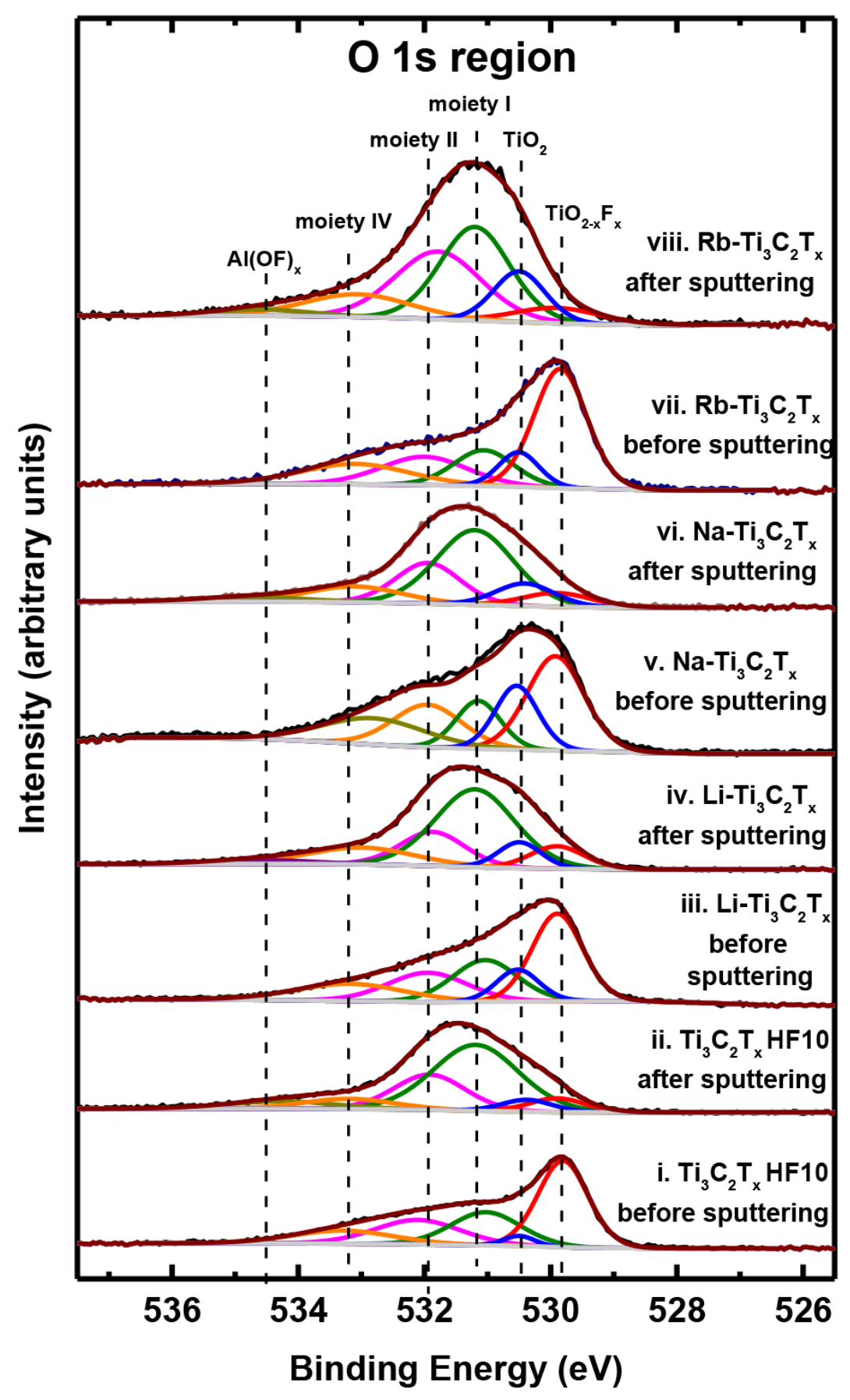

Figure S6. XPS spectra with curve-fitting for $\mathrm{O} 1 \mathrm{~s}$ region for (i) $\mathrm{Ti}_{3} \mathrm{C}_{2} \mathrm{~T}_{\mathrm{x}}$ HF10 before sputtering; (ii) $\mathrm{Ti}_{3} \mathrm{C}_{2} \mathrm{~T}_{\mathrm{x}}$

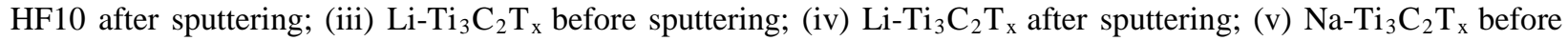
sputtering; (vi) $\mathrm{Na}_{-} \mathrm{Ti}_{3} \mathrm{C}_{2} \mathrm{~T}_{\mathrm{x}}$ after sputtering; (vii) $\mathrm{Rb}-\mathrm{Ti}_{3} \mathrm{C}_{2} \mathrm{~T}_{\mathrm{x}}$ before sputtering; and (viii) $\mathrm{Rb}^{-} \mathrm{Ti}_{3} \mathrm{C}_{2} \mathrm{~T}_{\mathrm{x}}$ after sputtering. Dashed vertical lines, from left to right, represent the species $\mathrm{Al}(\mathrm{OF})_{\mathrm{x}}$ (due to byproducts of etching), $\mathrm{H}_{2} \mathrm{O}_{\text {ads }}$ (moiety IV, $\mathrm{H}_{2} \mathrm{O}$ adsorbed on the $\mathrm{OH}$ termination of $\mathrm{Ti}_{3} \mathrm{C}_{2}$ ), $\mathrm{Ti}_{3} \mathrm{C}_{2}(\mathrm{OH})_{\mathrm{x}}$ (moiety II, OH termination of $\mathrm{Ti}_{3} \mathrm{C}_{2}$ ), $\mathrm{Ti}_{3} \mathrm{C}_{2} \mathrm{O}_{\mathrm{x}}$ (moiety I, O termination of $\mathrm{Ti}_{3} \mathrm{C}_{2}$ ), $\mathrm{TiO}_{2}$ (surface oxide), and $\mathrm{TiO}_{2-\mathrm{x}} \mathrm{F}_{\mathrm{x}}$ (surface oxide). Table S10 identifies and quantifies the various components shown. 
Table S10: XPS peak fitting results for $\mathrm{O} 1 \mathrm{~s}$ region of various $\mathrm{Ti}_{3} \mathrm{C}_{2} \mathrm{~T}_{\mathrm{x}}$ samples before and after sputtering

\begin{tabular}{|c|c|c|c|c|c|}
\hline Sample & BE [eV] & FWHM [eV] & Fraction & Assigned to & Reference \\
\hline \multirow{5}{*}{$\begin{array}{l}\mathbf{T i}_{3} \mathbf{C}_{2} \mathbf{T}_{\mathbf{x}} \mathbf{H F 1 0} \text {, } \\
\text { before sputtering }\end{array}$} & 529.8 & 0.9 & 0.42 & $\mathrm{TiO}_{2}$ & 4,7 \\
\hline & 530.5 & 0.6 & 0.03 & $\mathrm{TiO}_{2}-\mathrm{F}$ & 5 \\
\hline & 531.0 & 1.3 & 0.22 & $\mathrm{C}-\mathrm{Ti}-\mathrm{O}_{\mathrm{x}}(\mathrm{I}) / \mathrm{OR}^{\mathrm{a}}$ & 2 \\
\hline & 532.1 & 1.6 & 0.20 & $\mathrm{C}-\mathrm{Ti}-(\mathrm{OH})_{\mathrm{x}}(\mathrm{II}) / \mathrm{OR}^{\mathrm{a}}$ & 2 \\
\hline & 533.3 & 1.9 & 0.13 & $\mathrm{H}_{2} \mathrm{O}_{\text {ads }}(\mathrm{IV}) / \mathrm{OR}^{\mathrm{a}}$ & 2 \\
\hline \multirow{6}{*}{$\begin{array}{l}\mathbf{T i}_{3} \mathbf{C}_{2} \mathbf{T}_{\mathbf{x}} \mathbf{H F 1 0} \text {, } \\
\text { after sputtering }\end{array}$} & 529.9 & 1.0 & 0.07 & $\mathrm{TiO}_{2}$ & 4,7 \\
\hline & 530.4 & 0.9 & 0.05 & $\mathrm{TiO}_{2}-\mathrm{F}$ & 5 \\
\hline & 531.2 & 1.6 & 0.51 & $\mathrm{C}-\mathrm{Ti}-\mathrm{O}_{\mathrm{x}}(\mathrm{I}) / \mathrm{OR}^{\mathrm{a}}$ & 2 \\
\hline & 531.9 & 1.3 & 0.22 & $\mathrm{C}-\mathrm{Ti}-(\mathrm{OH})_{\mathrm{x}}(\mathrm{II}) / \mathrm{OR}^{\mathrm{a}}$ & 2 \\
\hline & 533.2 & 1.7 & 0.08 & $\mathrm{H}_{2} \mathrm{O}_{\text {ads }}(\mathrm{IV}) / \mathrm{OR}^{\mathrm{a}}$ & 2 \\
\hline & 534.4 & 2.0 & 0.07 & $\mathrm{Al}(\mathrm{OF})_{\mathrm{x}}$ & 8 \\
\hline \multirow{5}{*}{$\begin{array}{l}\mathbf{L i}-\mathbf{T i} \mathbf{i}_{3} \mathbf{C}_{2} \mathbf{T}_{\mathbf{x}} \text {, } \\
\text { before sputtering }\end{array}$} & 529.9 & 0.9 & 0.35 & $\mathrm{TiO}_{2}$ & 4,7 \\
\hline & 530.5 & 0.8 & 0.11 & $\mathrm{TiO}_{2}-\mathrm{F}$ & 5 \\
\hline & 531.0 & 1.2 & 0.21 & $\mathrm{C}-\mathrm{Ti}-\mathrm{O}_{\mathrm{x}}(\mathrm{I}) / \mathrm{OR}^{\mathrm{a}}$ & 2 \\
\hline & 532.0 & 1.5 & 0.18 & $\mathrm{C}-\mathrm{Ti}-(\mathrm{OH})_{\mathrm{x}}(\mathrm{II}) / \mathrm{OR}^{\mathrm{a}}$ & 2 \\
\hline & 533.2 & 2.0 & 0.15 & $\mathrm{H}_{2} \mathrm{O}_{\text {ads }}(\mathrm{IV}) / \mathrm{OR}^{\mathrm{a}}$ & 2 \\
\hline \multirow{6}{*}{$\begin{array}{l}\mathbf{L i}-\mathbf{T i}_{3} \mathbf{C}_{2} \mathbf{T}_{\mathbf{x}} \text {, } \\
\text { after sputtering }\end{array}$} & 529.9 & 1.0 & 0.08 & $\mathrm{TiO}_{2}$ & 4,7 \\
\hline & 530.5 & 0.8 & 0.06 & $\mathrm{TiO}_{2}-\mathrm{F}$ & 5 \\
\hline & 531.2 & 1.5 & 0.57 & $\mathrm{C}-\mathrm{Ti}-\mathrm{O}_{\mathrm{x}}(\mathrm{I}) / \mathrm{OR}^{\mathrm{a}}$ & 2 \\
\hline & 531.9 & 1.2 & 0.14 & $\mathrm{C}-\mathrm{Ti}-(\mathrm{OH})_{\mathrm{x}}(\mathrm{II}) / \mathrm{OR}^{\mathrm{a}}$ & 2 \\
\hline & 533.0 & 2.0 & 0.11 & $\mathrm{H}_{2} \mathrm{O}_{\text {ads }}(\mathrm{IV}) / \mathrm{OR}^{\mathrm{a}}$ & 2 \\
\hline & 534.6 & 1.9 & 0.03 & $\mathrm{Al}(\mathrm{OF})_{\mathrm{x}}$ & 8 \\
\hline \multirow{5}{*}{$\begin{array}{l}\mathbf{N a - T i}{ }_{3} \mathbf{C}_{2} \mathbf{T}_{\mathbf{x}} \text {, } \\
\text { before sputtering }\end{array}$} & 529.9 & 1.1 & 0.33 & $\mathrm{TiO}_{2}$ & 4,7 \\
\hline & 530.5 & 0.8 & 0.17 & $\mathrm{TiO}_{2}-\mathrm{F}$ & 5 \\
\hline & 531.1 & 0.8 & 0.13 & $\mathrm{C}-\mathrm{Ti}-\mathrm{O}_{\mathrm{x}}(\mathrm{I}) / \mathrm{OR}^{\mathrm{a}}$ & 2 \\
\hline & 532.0 & 1.3 & 0.20 & $\mathrm{C}-\mathrm{Ti}-(\mathrm{OH})_{\mathrm{x}}(\mathrm{II}) / \mathrm{OR}^{\mathrm{a}}$ & 2 \\
\hline & 532.8 & 1.9 & 0.17 & $\mathrm{H}_{2} \mathrm{O}_{\text {ads }}(\mathrm{IV}) / \mathrm{OR}^{\mathrm{a}}$ & 2 \\
\hline \multirow{6}{*}{$\begin{array}{l}\mathbf{N a}-\mathbf{T i}_{3} \mathbf{C}_{2} \mathbf{T}_{\mathbf{x}}, \\
\text { after sputtering }\end{array}$} & 529.9 & 1.3 & 0.07 & $\mathrm{TiO}_{2}$ & 4,7 \\
\hline & 530.4 & 1.1 & 0.10 & $\mathrm{TiO}_{2}-\mathrm{F}$ & 5 \\
\hline & 531.2 & 1.4 & 0.46 & $\mathrm{C}-\mathrm{Ti}-\mathrm{O}_{\mathrm{x}}(\mathrm{I}) / \mathrm{OR}^{\mathrm{a}}$ & 2 \\
\hline & 531.9 & 1.2 & 0.21 & $\mathrm{C}-\mathrm{Ti}-(\mathrm{OH})_{\mathrm{x}}(\mathrm{II}) / \mathrm{OR}^{\mathrm{a}}$ & 2 \\
\hline & 533.1 & 1.8 & 0.12 & $\mathrm{H}_{2} \mathrm{O}_{\text {ads }}(\mathrm{IV}) / \mathrm{OR}^{\mathrm{a}}$ & 2 \\
\hline & 534.8 & 2.0 & 0.04 & $\mathrm{Al}(\mathrm{OF})_{\mathrm{x}}$ & 8 \\
\hline \multirow{5}{*}{$\begin{array}{l}\mathbf{R b}-\mathbf{T i} \mathbf{i}_{3} \mathbf{C}_{2} \mathbf{T}_{\mathbf{x}} \text {, } \\
\text { before sputtering }\end{array}$} & 529.8 & 1.1 & 0.43 & $\mathrm{TiO}_{2}$ & 4,7 \\
\hline & 530.5 & 0.8 & 0.10 & $\mathrm{TiO}_{2}-\mathrm{F}$ & 5 \\
\hline & 531.1 & 1.1 & 0.15 & $\mathrm{C}-\mathrm{Ti}-\mathrm{O}_{\mathrm{x}}(\mathrm{I}) / \mathrm{OR}^{\mathrm{a}}$ & 2 \\
\hline & 532.0 & 1.6 & 0.17 & $\mathrm{C}-\mathrm{Ti}-(\mathrm{OH})_{\mathrm{x}}(\mathrm{II}) / \mathrm{OR}^{\mathrm{a}}$ & 2 \\
\hline & 533.1 & 2.0 & 0.15 & $\mathrm{H}_{2} \mathrm{O}_{\text {ads }}(\mathrm{IV}) / \mathrm{OR}^{\mathrm{a}}$ & 2 \\
\hline \multirow{6}{*}{$\begin{array}{l}\mathbf{R b}-\mathbf{T i}_{3} \mathbf{C}_{2} \mathbf{T}_{\mathbf{x}}, \\
\text { after sputtering }\end{array}$} & 529.9 & 1.6 & 0.07 & $\mathrm{TiO}_{2}$ & 4,7 \\
\hline & 530.5 & 1.1 & 0.13 & $\mathrm{TiO}_{2}-\mathrm{F}$ & 5 \\
\hline & 531.2 & 1.3 & 0.34 & C-Ti-O ${ }_{x}(\mathrm{I}) / \mathrm{OR}^{\mathrm{a}}$ & 2 \\
\hline & 531.8 & 1.6 & 0.30 & C-Ti- $(\mathrm{OH})_{\mathrm{x}}(\mathrm{II}) / \mathrm{OR}^{\mathrm{a}}$ & 2 \\
\hline & 533.1 & 2.0 & 0.13 & $\mathrm{H}_{2} \mathrm{O}_{\text {ads }}(\mathrm{IV}) / \mathrm{OR}^{\mathrm{a}}$ & 2 \\
\hline & 534.6 & 1.8 & 0.03 & $\mathrm{Al}(\mathrm{OF})_{\mathrm{x}}$ & 8 \\
\hline
\end{tabular}

${ }^{\mathrm{a}}$ OR stands for organic compounds due to atmospheric surface contaminations. 


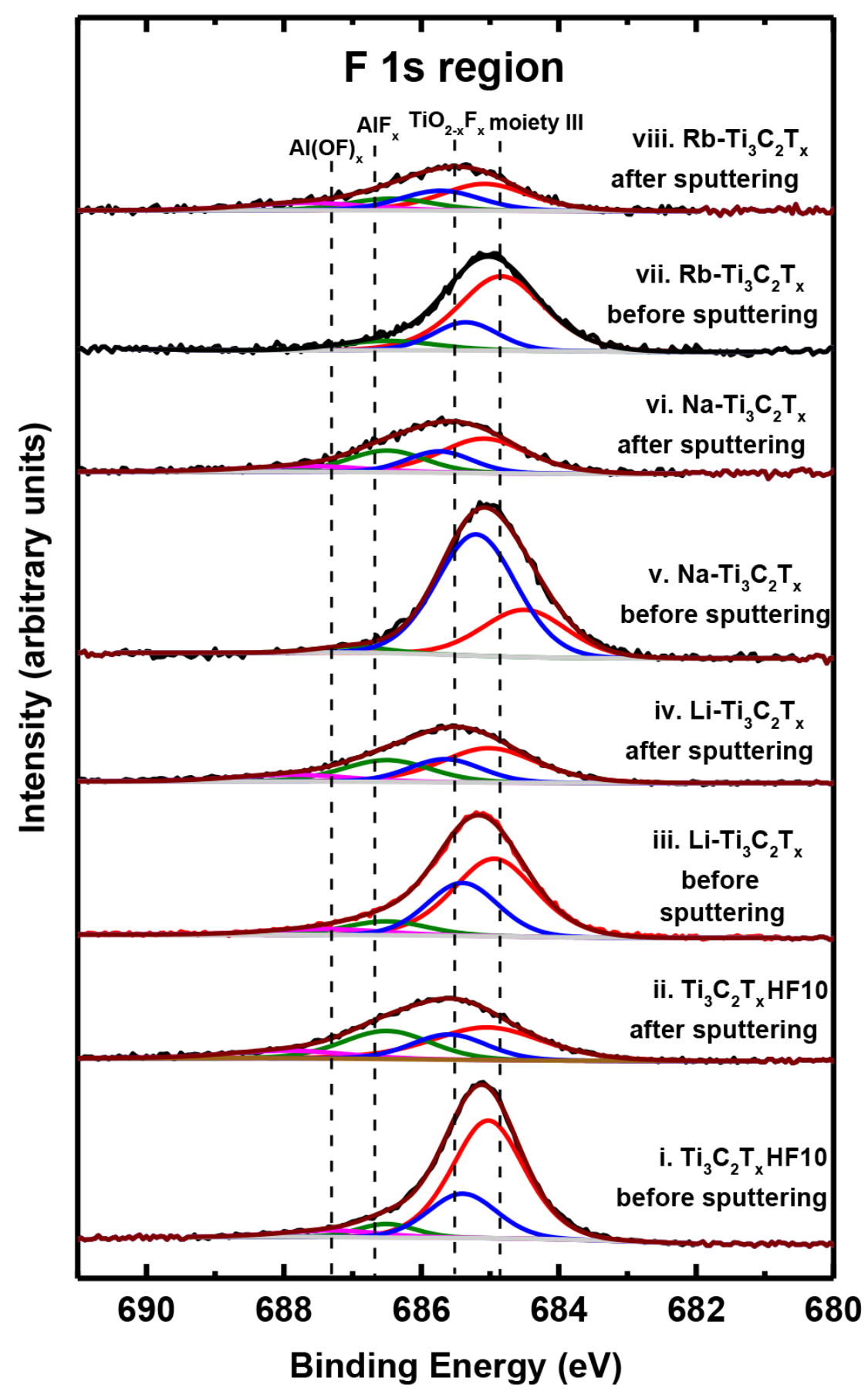

Figure S7. XPS spectra with curve-fitting for $\mathrm{F} 1$ s region for (i) $\mathrm{Ti}_{3} \mathrm{C}_{2} \mathrm{~T}_{\mathrm{x}}$ HF10 before sputtering; (ii) $\mathrm{Ti}_{3} \mathrm{C}_{2} \mathrm{~T}_{\mathrm{x}}$

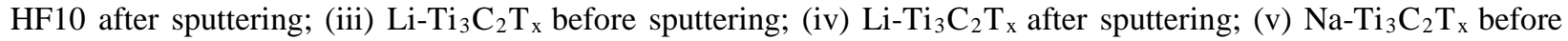
sputtering; (vi) Na-Ti ${ }_{3} \mathrm{C}_{2} \mathrm{~T}_{\mathrm{x}}$ after sputtering; (vii) $\mathrm{Rb}-\mathrm{Ti}_{3} \mathrm{C}_{2} \mathrm{~T}_{\mathrm{x}}$ before sputtering; and (viii) $\mathrm{Rb}-\mathrm{Ti}_{3} \mathrm{C}_{2} \mathrm{~T}_{\mathrm{x}}$ after sputtering. Dashed vertical lines, from left to right, represent the species $\mathrm{Al}(\mathrm{OF})_{\mathrm{x}}$ (due to byproducts of etching), the species $\mathrm{AlF}_{\mathrm{x}}$ (due to byproducts of etching), $\mathrm{TiO}_{2-\mathrm{x}} \mathrm{F}_{\mathrm{x}}$ (surface oxide), and $\mathrm{Ti}_{3} \mathrm{C}_{2}(\mathrm{~F})_{\mathrm{x}}$ (moiety III, $\mathrm{F}$ termination of $\mathrm{Ti}_{3} \mathrm{C}_{2}$ ).Table $\mathrm{S} 11$ identifies and quantifies the various components shown. 
Table S11: XPS peak fitting results for $\mathrm{F} 1 \mathrm{~s}$ region of various $\mathrm{Ti}_{3} \mathrm{C}_{2} \mathrm{~T}_{\mathrm{x}}$ before and after sputtering

\begin{tabular}{|c|c|c|c|c|c|}
\hline Sample & BE [eV] & FWHM [eV] & Fraction & Assigned to & Reference \\
\hline \multirow{4}{*}{$\begin{array}{l}\mathbf{T i}_{3} \mathbf{C}_{2} \mathbf{T}_{\mathbf{x}} \mathbf{H F 1 0} \text {, } \\
\text { before sputtering }\end{array}$} & 685.0 & 1.2 & 0.66 & C-Ti-F ${ }_{x}$ (III) & 2 \\
\hline & 685.4 & 1.2 & 0.23 & $\mathrm{TiO}_{2}-\mathrm{F}$ & 5 \\
\hline & 686.5 & 1.0 & 0.06 & $\mathrm{AlF}_{\mathrm{x}}$ & 8 \\
\hline & 687.3 & 1.7 & 0.05 & $\mathrm{Al}(\mathrm{OF})_{\mathrm{x}}$ & 8 \\
\hline \multirow{4}{*}{$\begin{array}{l}\mathbf{T i}_{3} \mathbf{C}_{2} \mathbf{T}_{\mathbf{x}} \mathbf{H F 1 0} \text {, } \\
\text { after sputtering }\end{array}$} & 685.0 & 1.9 & 0.42 & C-Ti-Fx (III) & 2 \\
\hline & 685.6 & 1.3 & 0.21 & $\mathrm{TiO}_{2}-\mathrm{F}$ & 5 \\
\hline & 686.5 & 1.5 & 0.27 & $\mathrm{AlF}_{\mathrm{x}}$ & 8 \\
\hline & 687.9 & 1.7 & 0.10 & $\mathrm{Al}(\mathrm{OF})_{\mathrm{x}}$ & 8 \\
\hline \multirow{4}{*}{$\begin{array}{l}\mathbf{L i}-\mathbf{T i}{ }_{3} \mathbf{C}_{2} \mathbf{T}_{\mathbf{x}}, \\
\text { before sputtering }\end{array}$} & 684.9 & 1.4 & 0.54 & C-Ti-Fx (III) & 2 \\
\hline & 685.4 & 1.2 & 0.31 & $\mathrm{TiO}_{2}-\mathrm{F} / \mathrm{LiF}$ & 5,9 \\
\hline & 686.5 & 1.4 & 0.09 & $\mathrm{AlF}_{\mathrm{x}}$ & 8 \\
\hline & 687.4 & 2.0 & 0.06 & $\mathrm{Al}(\mathrm{OF})_{\mathrm{x}}$ & 8 \\
\hline \multirow{4}{*}{$\begin{array}{l}\mathbf{L i}-\mathbf{T i}_{3} \mathbf{C}_{2} \mathbf{T}_{\mathbf{x}} \text {, } \\
\text { after sputtering }\end{array}$} & 685.0 & 1.7 & 0.43 & C-Ti-Fx (III) & 2 \\
\hline & 685.6 & 1.3 & 0.22 & $\mathrm{TiO}_{2}-\mathrm{F} / \mathrm{LiF}$ & 5,9 \\
\hline & 686.5 & 1.5 & 0.25 & $\mathrm{AlF}_{\mathrm{X}}$ & 8,9 \\
\hline & 687.9 & 2.0 & 0.10 & $\mathrm{Al}(\mathrm{OF})_{\mathrm{x}}$ & 8 \\
\hline \multirow{3}{*}{$\begin{array}{l}\mathbf{N a -} \mathbf{T i}_{3} \mathbf{C}_{2} \mathbf{T}_{\mathbf{x}} \text {, } \\
\text { before sputtering }\end{array}$} & 684.5 & 1.4 & 0.28 & C-Ti-F ${ }_{x}$ (III) & 2 \\
\hline & 685.2 & 1.4 & 0.69 & $\mathrm{TiO}_{2}-\mathrm{F}$ & 5 \\
\hline & 687.0 & 1.2 & 0.03 & $\mathrm{Al}(\mathrm{OF})_{\mathrm{x}}$ & 8 \\
\hline \multirow{4}{*}{$\begin{array}{l}\mathbf{N a}-\mathbf{T i}_{3} \mathbf{C}_{2} \mathbf{T}_{\mathbf{x}}, \\
\text { after sputtering }\end{array}$} & 685.1 & 1.5 & 0.46 & C-Ti-Fx (III) & 2 \\
\hline & 685.7 & 1.1 & 0.20 & $\mathrm{TiO}_{2}-\mathrm{F} / \mathrm{LiF}$ & 5,9 \\
\hline & 686.5 & 1.3 & 0.24 & $\mathrm{AlF}_{\mathrm{x}}$ & 8,9 \\
\hline & 687.7 & 2.0 & 0.10 & $\mathrm{Al}(\mathrm{OF})_{\mathrm{x}}$ & 8 \\
\hline \multirow{3}{*}{$\begin{array}{l}\mathbf{R b}-\mathbf{T i}_{3} \mathbf{C}_{2} \mathbf{T}_{\mathbf{x}} \text {, } \\
\text { before sputtering }\end{array}$} & 684.8 & 1.5 & 0.70 & C-Ti-F ${ }_{x}(\mathrm{III})$ & 2 \\
\hline & 685.4 & 1.1 & 0.20 & $\mathrm{TiO}_{2}-\mathrm{F} / \mathrm{LiF}$ & 5,9 \\
\hline & 686.5 & 1.7 & 0.10 & $\mathrm{AlF}_{\mathrm{x}}$ & 8,9 \\
\hline \multirow{4}{*}{$\begin{array}{l}\mathbf{R b}-\mathbf{T i}_{3} \mathbf{C}_{2} \mathbf{T}_{\mathbf{x}} \text {, } \\
\text { after sputtering }\end{array}$} & 685.1 & 1.5 & 0.41 & C-Ti-Fx (III) & 2 \\
\hline & 685.7 & 1.4 & 0.27 & $\mathrm{TiO}_{2}-\mathrm{F} / \mathrm{LiF}$ & 5,9 \\
\hline & 686.4 & 1.5 & 0.17 & $\mathrm{AlF}_{\mathrm{x}}$ & 8,9 \\
\hline & 687.7 & 2.0 & 0.15 & $\mathrm{Al}(\mathrm{OF})_{\mathrm{x}}$ & 8 \\
\hline
\end{tabular}




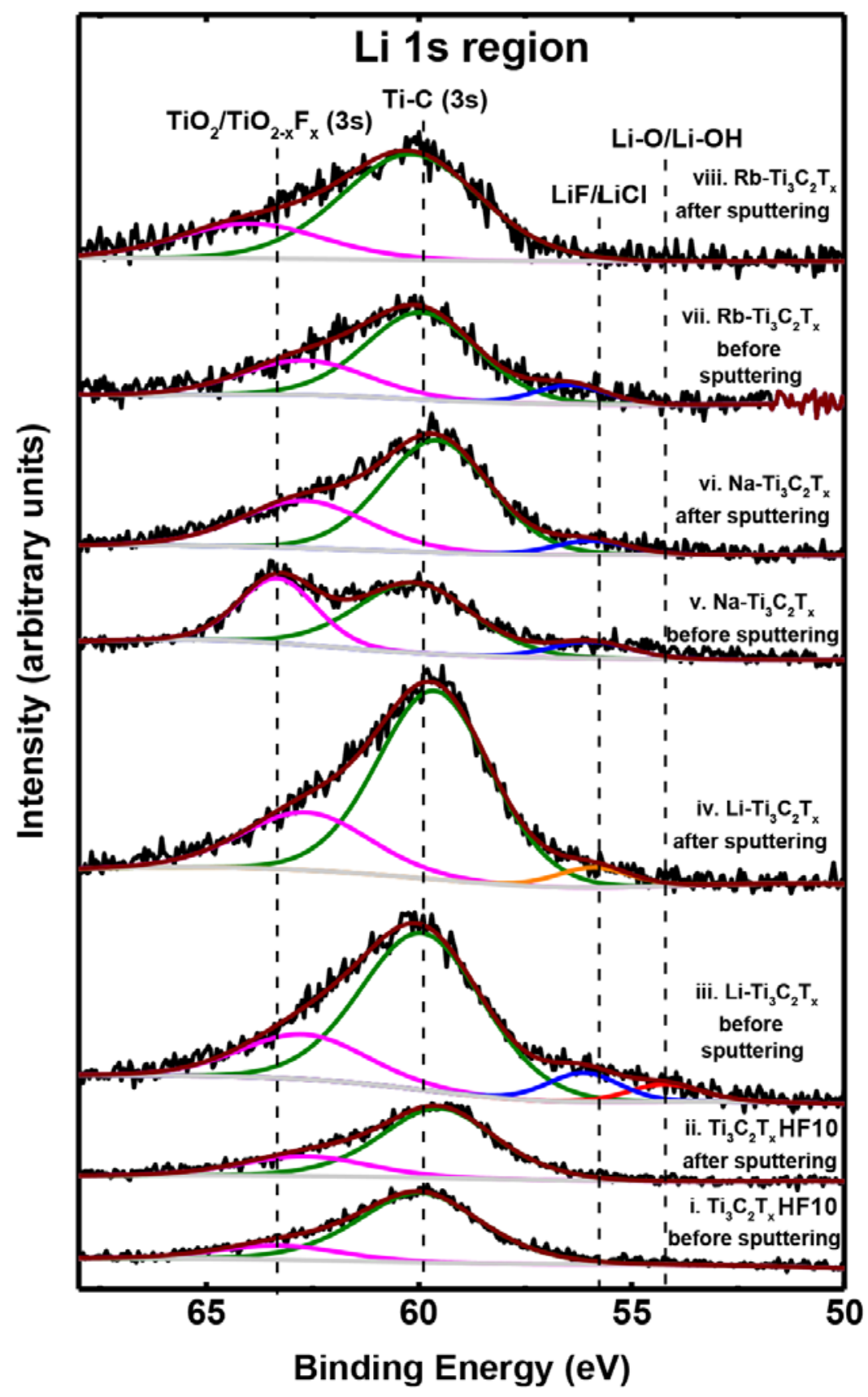

Figure S8. XPS spectra with curve-fitting for Li 1s region for (i) $\mathrm{Ti}_{3} \mathrm{C}_{2} \mathrm{~T}_{\mathrm{x}}$ HF10 before sputtering; (ii) $\mathrm{Ti}_{3} \mathrm{C}_{2} \mathrm{~T}_{\mathrm{x}}$

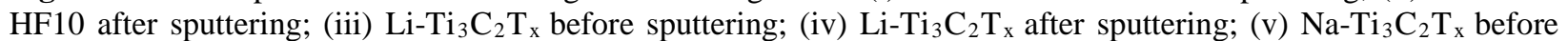
sputtering; (vi) Na-Ti ${ }_{3} \mathrm{C}_{2} \mathrm{~T}_{\mathrm{x}}$ after sputtering; (vii) $\mathrm{Rb}-\mathrm{Ti}_{3} \mathrm{C}_{2} \mathrm{~T}_{\mathrm{x}}$ before sputtering; and (viii) $\mathrm{Rb}-\mathrm{Ti}_{3} \mathrm{C}_{2} \mathrm{~T}_{\mathrm{x}}$ after sputtering. Dashed vertical lines, from left to right, repreent the species $\mathrm{TiO}_{2} / \mathrm{TiO}_{2-\mathrm{x}} \mathrm{F}_{\mathrm{x}}$ ( $\mathrm{Ti} 3 \mathrm{~s}$ ) surface oxide, Ti-C ( $\mathrm{Ti} 3 \mathrm{~s}$ ) titanium species in $\mathrm{MXene}, \mathrm{LiF} / \mathrm{LiCl}$ and $\mathrm{LiOH} / \mathrm{Li}_{2} \mathrm{O}$.Table $\mathrm{S} 12$ identifies and quantifies the various components shown. 
Table S12: XPS peak fitting results for $\mathrm{Li} 1 \mathrm{~s}$ region of various $\mathrm{Ti}_{3} \mathrm{C}_{2} \mathrm{~T}_{\mathrm{x}}$ before and after sputtering

\begin{tabular}{|c|c|c|c|c|c|}
\hline Sample & BE [eV] & FWHM [eV] & Fraction & Assigned to & Reference \\
\hline \multirow{2}{*}{$\begin{array}{l}\mathbf{T i}_{3} \mathbf{C}_{2} \mathbf{T}_{\mathbf{x}} \mathbf{H F 1 0} \text {, } \\
\text { before sputtering }\end{array}$} & 60.0 & 3.4 & & Ti-C (Ti 3s) & 10,11 \\
\hline & 63.3 & 3.4 & & $\mathrm{TiO}_{2} / \mathrm{T}_{\mathrm{i} 3} \mathrm{C}_{2} \mathrm{~F}_{\mathrm{x}}(\mathrm{Ti} 3 \mathrm{~s})$ & 10,11 \\
\hline \multirow{2}{*}{$\begin{array}{c}\mathbf{T i}_{3} \mathbf{C}_{2} \mathbf{T}_{\mathbf{x}} \mathbf{H F 1 0} \text {, } \\
\text { after sputtering }\end{array}$} & 59.5 & 3.2 & & Ti-C (Ti 3s) & 10,11 \\
\hline & 62.7 & 3.5 & & $\mathrm{TiO}_{2} / \mathrm{Ti}_{3} \mathrm{C}_{2} \mathrm{~F}_{\mathrm{x}}(\mathrm{Ti} 3 \mathrm{~s})$ & 10,11 \\
\hline \multirow{4}{*}{$\begin{array}{c}\mathbf{L i} \mathbf{i}-\mathbf{T i}_{3} \mathbf{C}_{2} \mathbf{T}_{\mathbf{x}} \text {, } \\
\text { before sputtering }\end{array}$} & 54.2 & 2.0 & 0.37 & $\mathrm{Li}-\mathrm{O} / \mathrm{Li}-\mathrm{OH}$ & 10,11 \\
\hline & 56.1 & 2.0 & 0.63 & $\mathrm{LiF} / \mathrm{LiCl}$ & 9 \\
\hline & 60.0 & 3.4 & & Ti-C (Ti 3s) & 10,11 \\
\hline & 63.3 & 3.5 & & $\mathrm{TiO}_{2} / \mathrm{Ti}_{3} \mathrm{C} 2 \mathrm{~F}_{\mathrm{x}}$ (Ti 3s) & 10,11 \\
\hline \multirow{3}{*}{$\begin{array}{c}\mathbf{L i} \mathbf{\mathbf { i }} \mathbf{\mathbf { T }} \mathbf{i}_{3} \mathbf{C}_{2} \mathbf{T}_{\mathbf{x}} \text {, } \\
\text { after sputtering }\end{array}$} & 55.9 & 2.0 & 1.00 & $\mathrm{Li}_{2} \mathrm{O} / \mathrm{LiOH}$ and $\mathrm{LiF} / \mathrm{LiCl}$ & \\
\hline & 59.6 & 3.2 & & Ti-C (Ti 3s) & 10,11 \\
\hline & 62.6 & 3.5 & & $\mathrm{TiO}_{2} / \mathrm{Ti}_{3} \mathrm{C}_{2} \mathrm{~F}_{\mathrm{x}}(\mathrm{Ti} 3 \mathrm{~s})$ & 10,11 \\
\hline \multirow{3}{*}{$\begin{array}{l}\mathbf{N a}-\mathbf{T i}_{3} \mathbf{C}_{2} \mathbf{T}_{\mathbf{x}} \text {, } \\
\text { before sputtering }\end{array}$} & 56.0 & 2.2 & 1.00 & $\mathrm{LiF} / \mathrm{LiCl}$ & 9 \\
\hline & 60.1 & 3.2 & & Ti-C (Ti 3s) & 10,11 \\
\hline & 63.3 & 2.2 & & $\mathrm{TiO}_{2} / \mathrm{Ti}_{3} \mathrm{C}_{2} \mathrm{~F}_{\mathrm{x}}(\mathrm{Ti} 3 \mathrm{~s})$ & 10,11 \\
\hline \multirow{3}{*}{$\begin{array}{l}\mathbf{N a}-\mathbf{T i}_{3} \mathbf{C}_{2} \mathbf{T}_{\mathbf{x}} \text {, } \\
\text { after sputtering }\end{array}$} & 56.0 & 2.0 & 1.00 & $\mathrm{LiF} / \mathrm{LiCl}$ & 9 \\
\hline & 59.6 & 3.0 & & Ti-C (Ti 3s) & 10,11 \\
\hline & 62.7 & 3.5 & & $\mathrm{TiO}_{2} / \mathrm{Ti}_{3} \mathrm{C}_{2} \mathrm{~F}_{\mathrm{x}}(\mathrm{Ti} 3 \mathrm{~s})$ & 10,11 \\
\hline \multirow{3}{*}{$\begin{array}{c}\mathbf{R b}-\mathbf{T i}_{3} \mathbf{C}_{2} \mathbf{T}_{\mathbf{x}} \text {, } \\
\text { before sputtering }\end{array}$} & 56.4 & 2.0 & 1.00 & $\mathrm{LiF} / \mathrm{LiCl}$ & 9 \\
\hline & 59.9 & 3.1 & & Ti-C (Ti 3s) & 10,11 \\
\hline & 62.7 & 3.5 & & $\mathrm{TiO}_{2} / \mathrm{Ti}_{3} \mathrm{C}_{2} \mathrm{~F}_{\mathrm{x}}(\mathrm{Ti} 3 \mathrm{~s})$ & 10,11 \\
\hline \multirow{2}{*}{$\begin{array}{l}\mathbf{R b}-\mathbf{T i}_{3} \mathbf{C}_{2} \mathbf{T}_{\mathbf{x}}, \\
\text { after sputtering }\end{array}$} & 60.2 & 3.9 & & Ti-C (Ti 3s) & 10,11 \\
\hline & 64.0 & 4.0 & & $\mathrm{TiO}_{2} / \mathrm{Ti}_{3} \mathrm{C}_{2} \mathrm{~F}_{\mathrm{x}}(\mathrm{Ti} 3 \mathrm{~s})$ & 10,11 \\
\hline
\end{tabular}




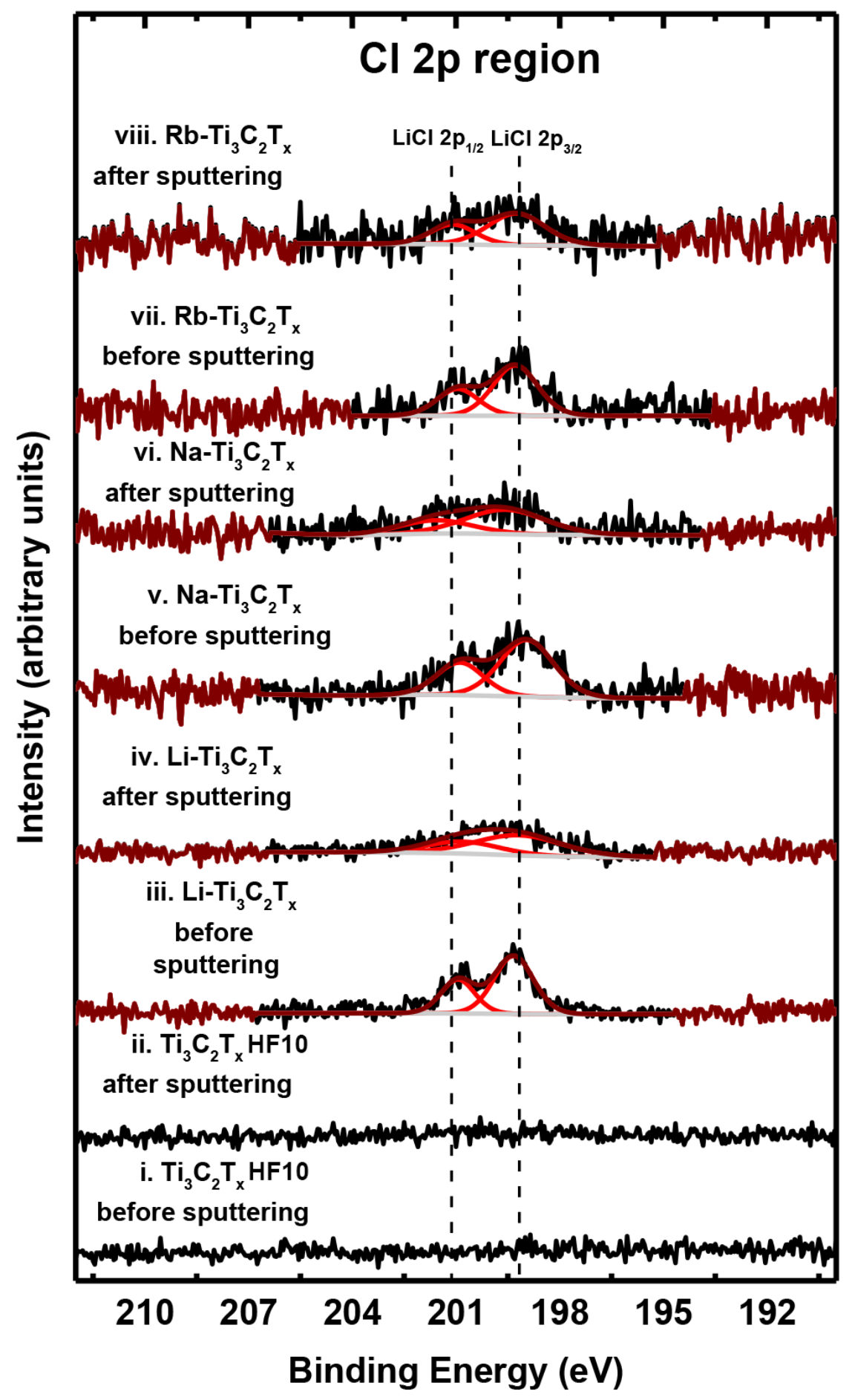

Figure S9. XPS spectra with curve-fitting for $\mathrm{Cl} 2 \mathrm{p}$ region for (i) $\mathrm{Ti}_{3} \mathrm{C}_{2} \mathrm{~T}_{\mathrm{x}}$ HF10 before sputtering; (ii) $\mathrm{Ti}_{3} \mathrm{C}_{2} \mathrm{~T}_{\mathrm{x}}$

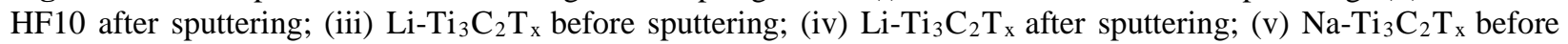
sputtering; (vi) Na-Ti ${ }_{3} \mathrm{C}_{2} \mathrm{~T}_{\mathrm{x}}$ after sputtering; (vii) Rb-Ti ${ }_{3} \mathrm{C}_{2} \mathrm{~T}_{\mathrm{x}}$ before sputtering, and (viii) $\mathrm{Rb}-\mathrm{Ti}_{3} \mathrm{C}_{2} \mathrm{~T}_{\mathrm{x}}$ after sputtering. Dashed vertical lines, from left to right, represent the species $\mathrm{LiCl}\left(2 \mathrm{p}_{1 / 2}\right)$ and $\mathrm{LiCl}\left(2 \mathrm{p}_{3 / 2}\right)$. Table S13 identifies and quantifies the various components shown. 
Table S13: XPS peak fitting results for $\mathrm{Cl} 2 \mathrm{p}$ region of various $\mathrm{Ti}_{3} \mathrm{C}_{2} \mathrm{~T}_{\mathrm{x}}$ before and after sputtering

\begin{tabular}{|c|c|c|c|c|c|}
\hline Sample & $\mathrm{BE}[\mathrm{eV}]^{\mathrm{a}}$ & FWHM $[e V]^{a}$ & Fraction & Assigned to & Reference \\
\hline $\begin{array}{l}\mathbf{T i}_{3} \mathbf{C}_{2} \mathbf{T}_{\mathbf{x}} \mathbf{H F 1 0} \text {, } \\
\text { before sputtering }\end{array}$ & 199.3 (200.9) & $1.3(1.1)$ & 1.00 & $\mathrm{LiCl}$ & 12 \\
\hline $\begin{array}{c}\mathbf{T i}_{3} \mathbf{C}_{2} \mathbf{T}_{\mathbf{x}} \mathbf{H F 1 0} \text {, } \\
\text { after sputtering }\end{array}$ & 199.4 (201.1) & $1.2(1.1)$ & 1.00 & $\mathrm{LiCl}$ & 12 \\
\hline $\begin{array}{c}\mathbf{L i}-\mathbf{T i}_{3} \mathbf{C}_{2} \mathbf{T}_{\mathbf{x}}, \\
\text { before sputtering }\end{array}$ & $199.4(201.1)$ & $1.2(1.1)$ & 1.00 & $\mathrm{LiCl}$ & 12 \\
\hline $\begin{array}{c}\mathbf{L i}-\mathbf{T i}_{3} \mathbf{C}_{2} \mathbf{T}_{\mathbf{x}}, \\
\text { after sputtering }\end{array}$ & $199.2(201.0)$ & $2.0(1.9)$ & 1.00 & $\mathrm{LiCl}$ & 12 \\
\hline $\begin{array}{c}\mathbf{N a}-\mathbf{T i}_{3} \mathbf{C}_{2} \mathbf{T}_{\mathbf{x}} \text {, } \\
\text { before sputtering }\end{array}$ & 199.0 (200.9) & $1.8(1.6)$ & 1.00 & $\mathrm{LiCl}$ & 12 \\
\hline $\begin{array}{l}\mathbf{N a}-\mathbf{T i}_{3} \mathbf{C}_{2} \mathbf{T}_{\mathbf{x}} \text {, } \\
\text { after sputtering }\end{array}$ & $199.6(201.6)$ & $1.5(1.3)$ & 1.00 & $\mathrm{LiCl}$ & 12 \\
\hline $\begin{array}{c}\mathbf{R b}-\mathbf{T i}_{3} \mathbf{C}_{2} \mathbf{T}_{\mathbf{x}} \text {, } \\
\text { before sputtering }\end{array}$ & $199.3(201.0)$ & $1.5(1.4)$ & 1.00 & $\mathrm{LiCl}$ & 12 \\
\hline $\begin{array}{l}\mathbf{R b}-\mathbf{T i}_{3} \mathbf{C}_{2} \mathbf{T}_{\mathbf{x}}, \\
\text { after sputtering }\end{array}$ & 199.3 (201.1) & $1.9(1.6)$ & 1.00 & $\mathrm{LiCl}$ & 12 \\
\hline
\end{tabular}

${ }^{\mathrm{a}}$ Values in parentheses correspond to the $2 \mathrm{p}_{1 / 2}$ component.

Table S14: XPS peak fitting results for $\mathrm{Rb} 3 \mathrm{~d}$ region of $\mathrm{Rb}-\mathrm{Ti}_{3} \mathrm{C}_{2} \mathrm{~T}_{\mathrm{x}}$ before and after sputtering

\begin{tabular}{cccccc}
\hline Sample & BE [eV] & FWHM [eV] & Fraction & Assigned to & Reference \\
\hline $\begin{array}{c}\text { Rb-Ti } \mathbf{C}_{2} \mathbf{T}_{\mathbf{x}}, \\
\text { before sputtering }\end{array}$ & $110.0(111.5)$ & $1.4(1.3)$ & 1.00 & $\mathrm{Rb}^{+}$ & 13 \\
\hline $\begin{array}{c}\mathbf{R b}-\mathbf{T i}_{3} \mathbf{C}_{2} \mathbf{T}_{\mathbf{x}}, \\
\text { after sputtering }\end{array}$ & $110.5(11.9)$ & $1.3(1.2)$ & 1.00 & $\mathrm{Rb}^{+}$ & 13 \\
\hline
\end{tabular}

${ }^{a}$ Values in parentheses correspond to the $3 \mathrm{~d}_{3 / 2}$ component.

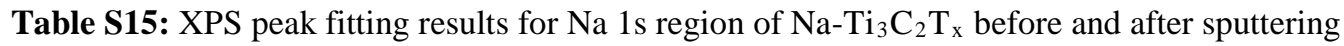

\begin{tabular}{|c|c|c|c|c|c|}
\hline Sample & BE [eV] & FWHM [eV] & Fraction & $\begin{array}{l}\text { Assigned to } \\
\end{array}$ & Reference \\
\hline \multirow{4}{*}{$\begin{array}{l}\mathbf{N a}-\mathbf{T i}_{3} \mathbf{C}_{2} \mathbf{T}_{\mathbf{x}} \\
\text { before sputtering }\end{array}$} & 1066.2 & 2.5 & & $\mathrm{TiO}_{2}$ (Auger LMM line) & 14 \\
\hline & 1069.2 & 3.3 & & Ti-C (Auger LMM line) & 14 \\
\hline & 1071.9 & 1.7 & 0.78 & $\mathrm{NaF} / \mathrm{NaCl}(\mathrm{Na} 1 \mathrm{~s})$ & $15-17$ \\
\hline & 1072.9 & 2.8 & 0.22 & $\mathrm{NaOH} / \mathrm{Na}_{2} \mathrm{O}(\mathrm{Na} 1 \mathrm{~s})$ & $15-17$ \\
\hline \multirow{4}{*}{$\begin{array}{l}\mathbf{N a -}-\mathbf{T i}_{3} \mathbf{C}_{2} \mathbf{T}_{\mathbf{x}}, \\
\text { after sputtering }\end{array}$} & 1066.6 & 2.8 & & $\mathrm{TiO}_{2}$ (Auger LMM line) & 14 \\
\hline & 1069.4 & 3.2 & & Ti-C (Auger LMM line) & 14 \\
\hline & 1072.3 & 2.3 & 0.70 & $\mathrm{NaF} / \mathrm{NaCl}(\mathrm{Na} 1 \mathrm{~s})$ & $15-17$ \\
\hline & 1073.4 & 2.5 & 0.30 & $\mathrm{NaOH} / \mathrm{Na}_{2} \mathrm{O}$ (Na 1s) & $15-17$ \\
\hline
\end{tabular}




\section{References}

(1) Smith, D. W. Ionic Hydration Enthalpies. J. Chem. Educ. 1977, 54, 540.

(2) J. Halim, K.M. Cook, M. Naguib, P. Eklund, Y. Gogtsi, J. Rosen and M.W. Barsoum. X-Ray Photoelectron Spectroscopy of Select Multi-Layered Transition Metal Carbides. Appl. Surf. Sci. 2016, 362, 406-417.

(3) Santerre, F.; Khakani, M. A. El; Chaker, M.; Dodelet, J. P. Properties of TiC Thin Films Grown by Pulsed Laser Deposition. Appl. Surf. Sci. 1999, 148, 24-33.

(4) Diebold, U. $\mathrm{TiO}_{2}$ by XPS. Surf. Sci. Spectra 1996, 4, 227.

(5) Tanuma, T.; Okamoto, H.; Ohnishi, K.; Morikawa, S.; Suzuki, T. Partially Fluorinated Metal Oxide Catalysts for a FriedelCrafts-Type Reaction of Dichlorofluoromethane with Tetrafluoroethylene. Catal. Lett. 2010, 136, 77-82.

(6) Jayaweera, P. M.; Quah, E. L.; Idriss, H. Photoreaction of Ethanol on $\mathrm{TiO}_{2}(110)$ Single-Crystal Surface. J. Phys. Chem. C 2007, 111, 1764-1769.

(7) Yamamoto, S.; Bluhm, H.; Andersson, K.; Ketteler, G.; Ogasawara, H.; Salmeron, M.; Nilsson, A. In Situ X-Ray Photoelectron Spectroscopy Studies of Water on Metals and Oxides at Ambient Conditions. J. Phys. Condens. Matter 2008, 20, 184025.

(8) Ernst, K.-H.; Grman, D.; Hauert, R.; Holländer, E. Fluorine-Induced Corrosion of Aluminium Microchip Bond Pads: An XPS and AES Analysis. Surf. Interface Anal. 1994, 21, 691-696.

(9) Niehoff, P.; Passerini, S.; Winter, M. Interface Investigations of a Commercial Lithium Ion Battery Graphite Anode Material by Sputter Depth Profile X-Ray Photoelectron Spectroscopy. Langmuir 2013, 29, 5806-5816.

(10) Theng, B. K. G.; Hayashi, S.; Soma, M.; Seyama, H. Nuclear Magnetic Resonance and X-Ray Photoelectron Spectroscopic Investigation of Lithium Migration in Montmorillonite. Clays Clay Miner. 1997, 45, 718-723.

(11) Ebina, T.; Iwasaki, T.; Chatterjee, A. XPS and DFT Study on the Migration of Lithium in Montmorillonite. Clay Sci. 1999, 10, 569-581.

(12) Kiyoshi Kanamura; Hiroshi Tamura; Zen-ichiro Takehara. XPS Analysis of a Lithium Surface Immersed in Propylene Carbonate Solution Containing Various Salts. J Electroanal Chem 1992, 333, 127-142.

(13) Guo, C.; Yin, S.; Dong, Q.; Sato, T. Near-Infrared Absorption Properties of RbxWO3 Nanoparticles. CrystEngComm 2012, 14, 7727-7732.

(14) Briggs, D.; Seah, M. P. Practical Surface Analysis, Auger and X-Ray Photoelectron Spectroscopy; Wiley, 1990.

(15) Citrin, P. H. High-Resolution X-Ray Photoemission from Sodium Metal and Its Hydroxide. Phys. Rev. B 1973, 8, 55455556.

(16) Nefedov, V. I.; Salyn, Y. V.; Leonhardt, G.; Scheibe, R. A Comparison of Different Spectrometers and Charge Corrections Used in X-Ray Photoelectron Spectroscopy. J. Electron Spectrosc. Relat. Phenom. 1977, 10, 121-124.

(17) Barrie, A.; Street, F. J. An Auger and X-Ray Photoelectron Spectroscopic Study of Sodium Metal and Sodium Oxide. J. Electron Spectrosc. Relat. Phenom. 1975, 7, 1-31. 